ARTICLE

Received 10 Aug 2013 | Accepted 16 Jan 2014 | Published 18 Feb 2014

DOI: $10.1038 /$ ncomms 4273

OPEN

\title{
Identification of renin progenitors in the mouse bone marrow that give rise to B-cell leukaemia
}

Brian C. Belyea ${ }^{1}$, Fang $\mathrm{Xu}^{1}$, Ellen S. Pentz ${ }^{1}$, Silvia Medrano${ }^{1}$, Minghong Li1, Yan $\mathrm{Hu}^{1}$, Stephen Turner ${ }^{2}$, Robin Legallo ${ }^{3}$, Craig A. Jones ${ }^{4}$, Joseph D. Tario ${ }^{4}$, Ping Liang ${ }^{5}$, Kenneth W. Gross ${ }^{4}$, Maria Luisa S. Sequeira-Lopez ${ }^{1}$ \& R. Ariel Gomez ${ }^{1}$

The cell of origin and triggering events for leukaemia are mostly unknown. Here we show that the bone marrow contains a progenitor that expresses renin throughout development and possesses a B-lymphocyte pedigree. This cell requires RBP-J to differentiate. Deletion of RBP-J in these renin-expressing progenitors enriches the precursor B-cell gene programme and constrains lymphocyte differentiation, facilitated by $\mathrm{H} 3 \mathrm{~K} 4 \mathrm{me} 3$ activating marks in genes that control the pre-B stage. Mutant cells undergo neoplastic transformation, and mice develop a highly penetrant B-cell leukaemia with multi-organ infiltration and early death. These reninexpressing cells appear uniquely vulnerable as other conditional models of RBP-J deletion do not result in leukaemia. The discovery of these unique renin progenitors in the bone marrow and the model of leukaemia described herein may enhance our understanding of normal and neoplastic haematopoiesis.

\footnotetext{
${ }^{1}$ Department of Pediatrics, University of Virginia School of Medicine, Charlottesville, Virginia 22908, USA. ${ }^{2}$ Department of Bioinformatics, University of Virginia School of Medicine, Charlottesville, Virginia 22908, USA. ${ }^{3}$ Department of Pathology, University of Virginia School of Medicine, Charlottesville, Virginia 22908, USA. ${ }^{4}$ Roswell Park Cancer Institute, Buffalo, New York 14263, USA. ${ }^{5}$ Department of Biological Sciences, Brock University, St Catharines, Ontario, L2S 3A1, Canada. Correspondence and requests for materials should be addressed to R.A.G. (email: rg@virginia.edu).
} 
$\mathrm{R}$ enin cells have traditionally been associated with the regulation of blood pressure and fluid-electrolyte homeostasis. Pursuing the mechanisms that regulate the identity of these cells, we uncovered an unexpected property of renin cells in the bone marrow with relevance to the development of malignancy. Renin progenitors appear early in the embryo and give rise to many different cell types throughout the body ${ }^{1}$. Whereas the function of renin cells in extra renal tissues is unclear, the ontogeny and function of renin cells in the kidney are better understood ${ }^{2-5}$. In the embryonic kidney, renin precursors are distributed extensively along nephrovascular units and participate in the assembly and branching morphogenesis of the kidney arterioles. As development of the kidney proceeds, renin precursors differentiate in situ into arteriolar smooth muscle cells, glomerular mesangial cells and interstitial pericytes. Thus, in the adult only a few cells at the tip of the renal arterioles near the glomeruli, the juxtaglomerular (JG) cells, retain the ability to synthesize and secrete renin upon physiological demands ${ }^{1}$. Under normal conditions, those cells suffice to regulate blood pressure and fluid-electrolyte homeostasis. However, if such adult animal is subjected to a homeostatic threat (such as hypotension, dehydration, sodium depletion or administration of reninangiotensin inhibitors), there is an increase in the number of renin-expressing cells along the arterioles, glomeruli and interstitium, resembling the embryonic pattern described above ${ }^{6,7}$. This phylogenetically conserved process occurs by re-transformation of arteriolar smooth muscle cells, mesangial cells and pericytes into renin-expressing cells ${ }^{1,8}$.

Because renin cells contain all the components of the Notch pathway including RBP-J, the final transcriptional effector of all the Notch receptors ${ }^{9}$, and Notch/RBP-J is known to regulate cell fate, we previously examined whether deletion of $R B P-J$ regulates the identity and plasticity of kidney renin cells during normal development and in response to a physiological threat. Conditional deletion of $R B P-J$ in renin-expressing cells resulted in a decrease in the number of renin-positive JG cells in the kidney and an inability of smooth muscle cells along the kidney vasculature to regain the renin phenotype ${ }^{10}$. Unexpectedly, as these mice aged beyond 6 months, they developed signs and symptoms of a highly penetrant and fulminant form of precursor B-lymphoblastic leukaemia. Given the potential medical relevance of this finding, in this study we perform an extensive series of experiments to fully characterize this mouse model of leukaemia, including its natural history and the genomic and epigenetic events underlying its development. We also set out to identify, and characterize in detail, which cells in the bone marrow are capable of producing renin under normal circumstances and whether those cells may be the origin of this striking model of leukaemia. Finally, we ascertain whether mutations in the $R B P-J$ gene are associated with leukaemia in humans as well. We find that renin is expressed by a subset of B-cell progenitors in the mouse bone marrow, and that these renin-expressing cells are the cell of origin for B-cell leukaemia when $R B P-J$ is deleted.

\section{Results}

Deletion of $R B P-J$ in renin cells results in B-cell leukaemia. We deleted RBP-J in cells of the renin-lineage by crossing mice that express Cre recombinase under control of the renin locus with $R B P-f^{f l f l}$ mice ${ }^{1,10,11}$. Mutant mice (RBP-fllfl; Ren $1^{\text {dcre/ }+}$ ) developed progressive abdominal distension and poor overall health by $\sim 6$ months of age (Fig. 1a). Necropsy demonstrated massive hepatosplenomegaly (spleen and liver weights were 15- and 4-fold higher than controls, respectively) (Fig. 1a-d). Mutant animals displayed marked leukocytosis and anaemia
(Fig. 1e), lymph node tumour formation (74\% of mutant mice developed axillary or retroperitoneal tumours) (Fig. 1f), and succumbed at an early age with a median survival of 269 days (Fig. 1g).

Blood smears from mutant mice demonstrated a predominance of lymphoblasts (Fig. 2a). Flow cytometry of bone marrow and tumours confirmed the presence of an aberrant B-lymphoid $\left(\mathrm{B} 220^{\mathrm{dim}} / \mathrm{CD} 19^{+}\right)$immunophenotype at the expense of myeloid cells compared with control mice (Fig. 2b). The phenotype was indicative of precursor B-cell leukaemia evidenced by the lack of IgM and IgD expressions (Fig. 2c). Similar findings were found in the spleen and peripheral blood of leukaemic animals (Supplementary Fig. 1a-c).

Given the presence of lymphoblasts within the blood and bone marrow and the extensive organomegaly, we performed a comprehensive histologic evaluation of mutant and control mice. The spleens of mutant mice were massively infiltrated with lymphoblasts resulting in defacement of their normal architecture without recognizable red or white pulp (Fig. 2d). Lymphoblasts invaded the liver in a periportal and perisinusoidal distribution (Fig. 2e) and kidney interstitium (Supplementary Fig. 2a). Mutant mice developed skin lesions (characterized by loss of fur, nodules and ulcerations due to epidermal and dermal lymphoblastic infiltration) and lymphoid tumours (Supplementary Fig. 2b,c). Finally, bone marrow from leukaemic animals was hypercellular compared with controls and consisted of a homogenous blast population that occupied over $90 \%$ of marrow space (Fig. 2f). These blasts replaced other haematopoietic cells explaining the marked anaemia found in mutant animals. Lymphoblasts displayed diffuse and strong immunoreactivity for PAX5 and CD79a, further confirming a B-cell lineage and expressed TdT and CD34 supporting a B-cell precursor maturational stage (Supplementary Fig. 2d-g).

To follow the distribution of mutant cells, we bred our mutant and control mice with $m T / m G$ reporter mice, which normally express RFP in all cells but GFP only in cells that express Cre recombinase. Therefore, cells harbouring the $R B P-J$ deletion are $\mathrm{GFP}^{+}$, whereas non-mutant leukocytes are $\mathrm{RFP}^{+12}$. The number of $\mathrm{GFP}^{+}$cells was markedly elevated in the blood and organs of mutant mice (Fig. $2 \mathrm{~g}$ ), indicating that deletion of RBP-J causes B-cell leukaemia with expansion of lymphoblasts to the bloodstream and invasion and morphological distortion of peripheral organs.

Following the current classification of murine lymphoid neoplasms, the majority (92\%) of mutant mice $(n=22)$ developed precursor B-cell lymphoblastic lymphoma/leukaemia (pre-B LBL $)^{13}$. A minority $(8 \%)$ of mice $(n=2)$ was affected by a myeloproliferative or mixed lymphoid/myeloid disorder and three animals developed mild disease. Given the striking predominance of the pre-B LBL, we focused our efforts on a detailed characterization of this phenotype.

We performed multiple experiments to investigate if this leukaemia model represents a clonal process and if the leukaemic cells can grow in a cell-autonomous manner in culture and transplant systems. First, analysis of immunoglobulin gene rearrangements was performed to determine the clonal nature of leukaemic cells. These studies demonstrated that B cells from the spleen and bone marrow of mutant animals had unique patterns of $\mathrm{V}(\mathrm{D}) \mathrm{J}_{\mathrm{H}}$ rearrangements when compared with wildtype animals, with a predominant recombination indicating mono- or oligo-clonal IgH patterns (Supplementary Fig. 3a-c). Next, we performed colony-forming assays from bone marrow cells of mutant mice to determine the clonogenic potential of leukaemic cells. Whereas wild-type bone marrow did not form colonies beyond the first passage, leukaemic cells continue to grow even after extensive passaging. At the time of writing this 
a

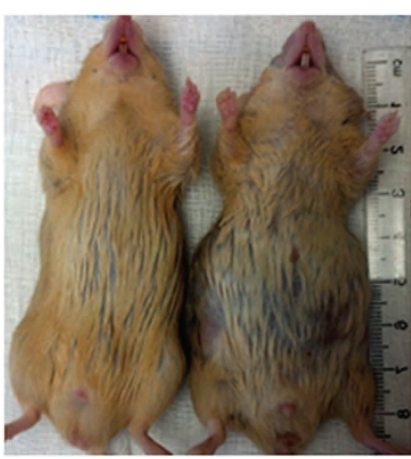

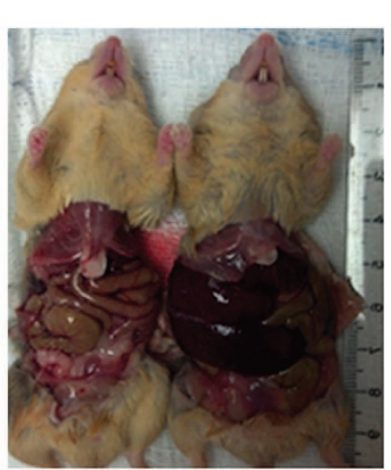

b

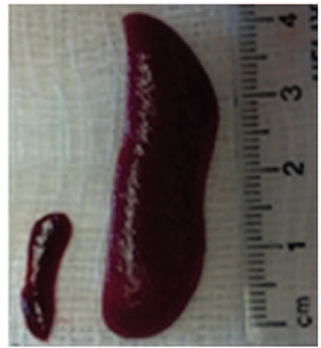

C
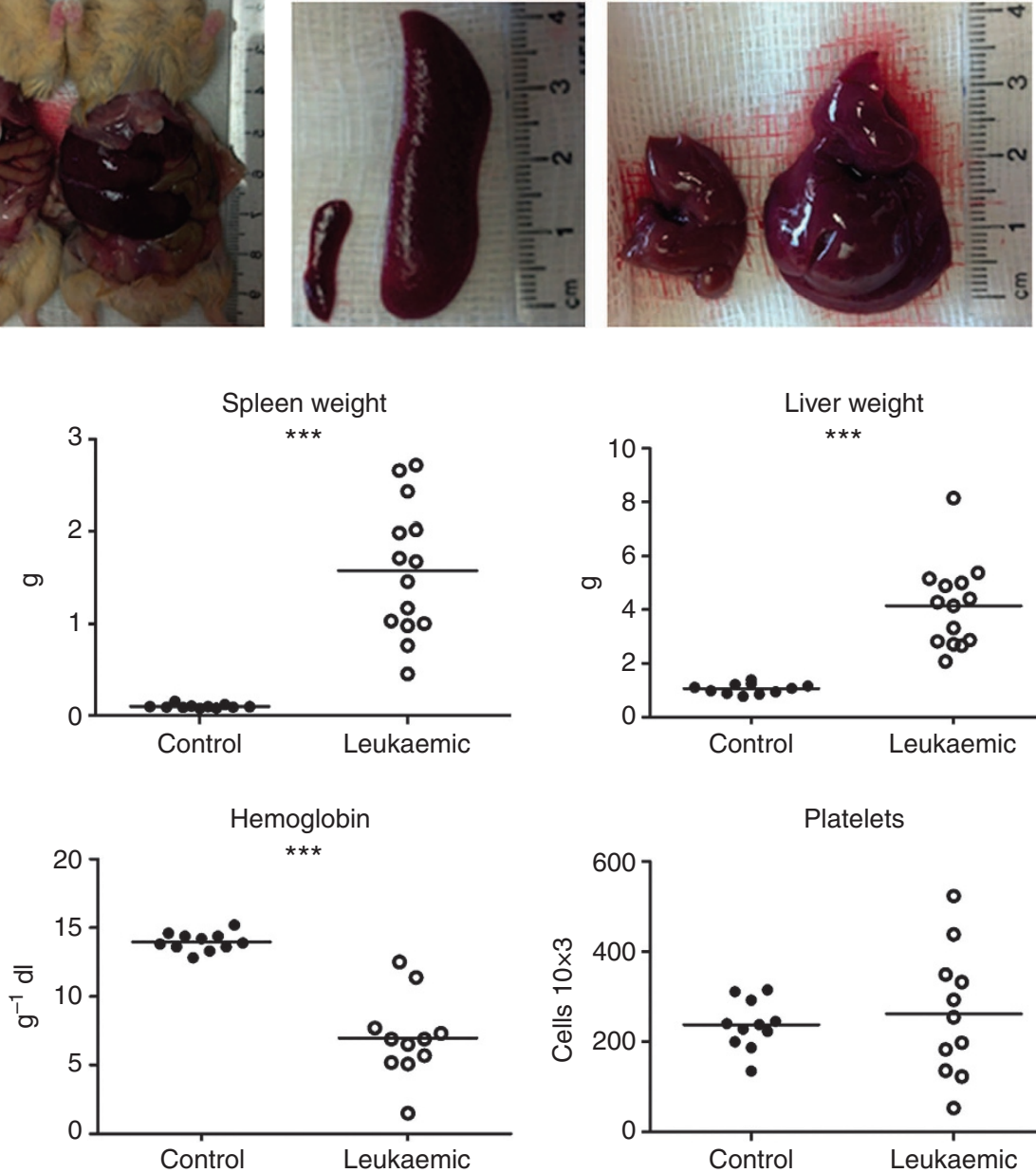

Liver weight

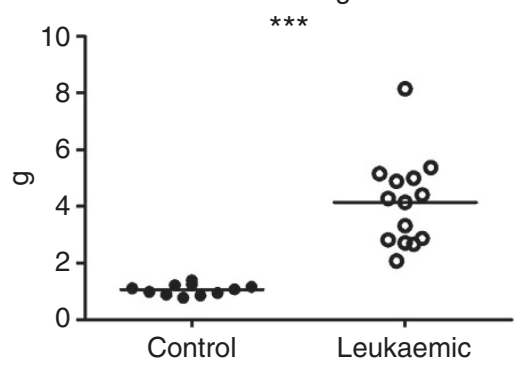

Platelets
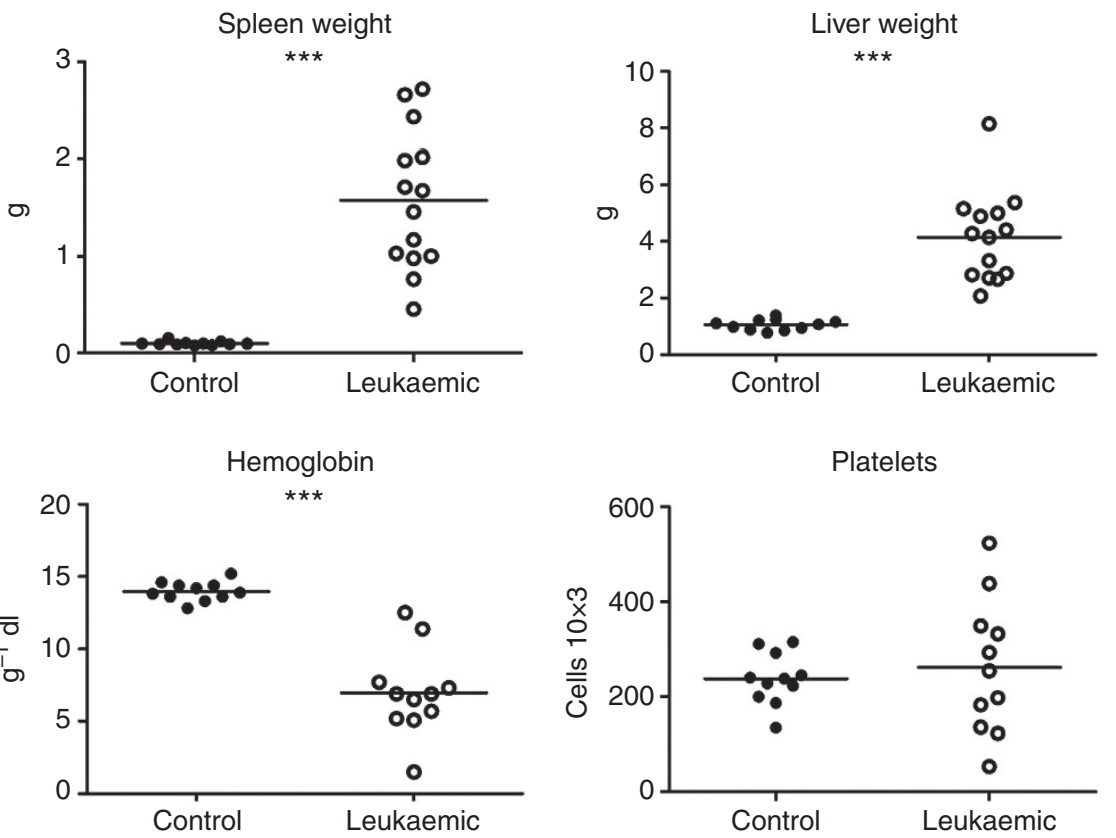

f

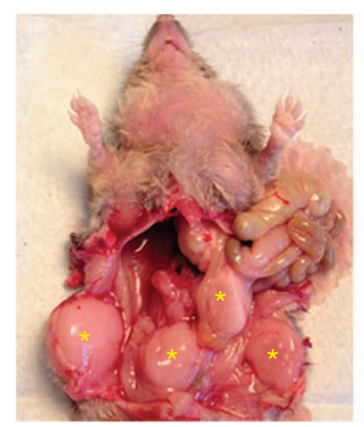

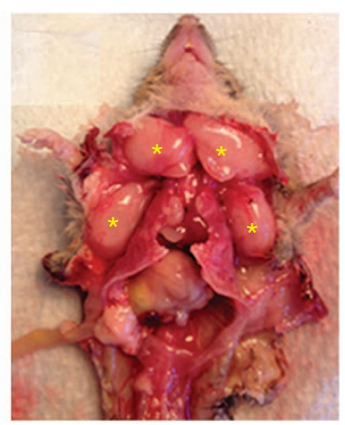

g

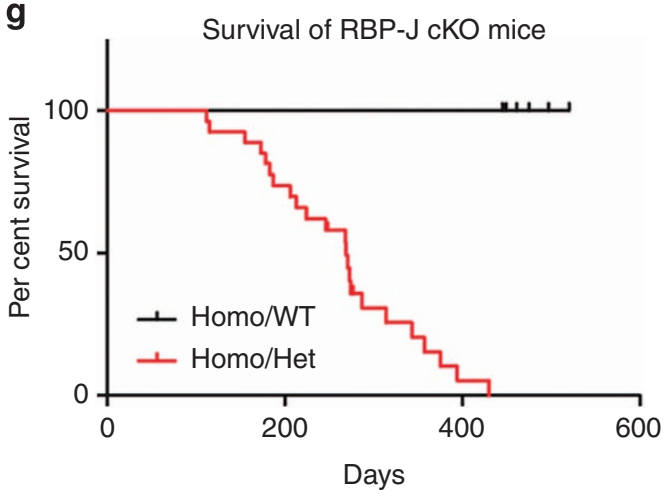

Figure 1 | Deletion of RBP-J in renin-lineage cells leads to tumour development and early death. (a) Mutant mice (right in both panels) develop abdominal distension compared with control mice (left in both panels) and necropsy demonstrated that abdominal distension was due to hepatosplenomegaly. (b) Representative picture of enlarged spleen from mutant mouse (right) compared with control (left). (c) Representative picture of the enlarged liver from mutant mouse (right) compared with control (left). (d) Leukaemic mice have statistically significant increased body, spleen and liver weights compared with control mice. Student's $t$-test; ${ }^{\star \star \star} P<0.001$ ( $n=11$ for control mice and $n=14$ for mutant mice). (e) The white blood cell (WBC) count is significantly higher and haemoglobin lower in leukaemic mice compared with controls. The platelet count is not significantly different between control and leukaemic mice. Horizontal lines represent the mean for each group in panels d-e. Student's $t$-test; ${ }^{\star \star \star} P<0.001$ ( $n=11$ for both control mice and mutant mice). (f) Lymphomatous tumours (yellow asterisks) at lower extremities, abdomen, anterior neck and upper extremities. Tumours were commonly found in the retroperitoneum just anterior to the vertebral column. (g) Kaplan-Meier survival curve showing early death of leukaemic mice compared with control mice. 
a

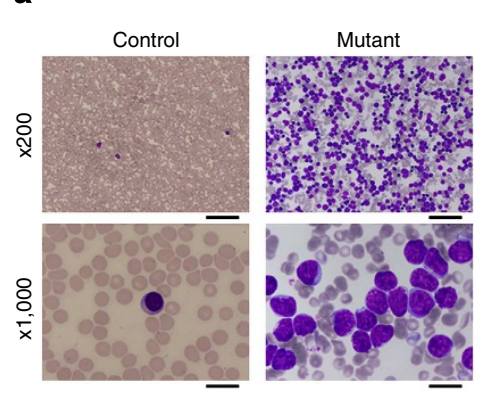

d

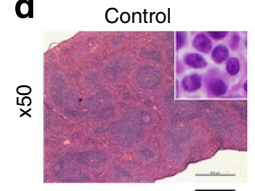

e Control

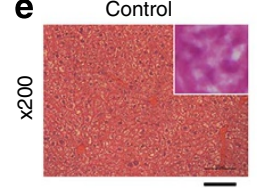

b

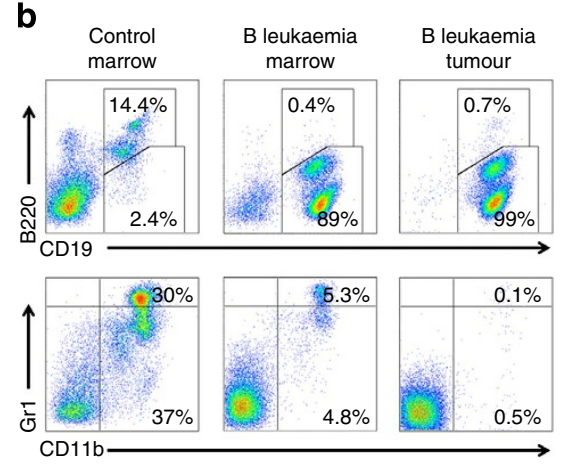

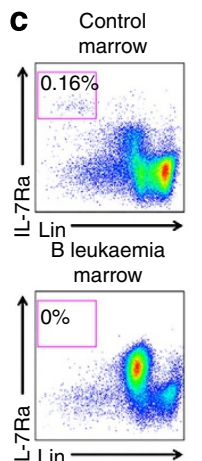

g f

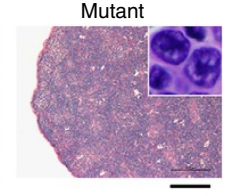

Mutant

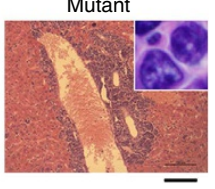

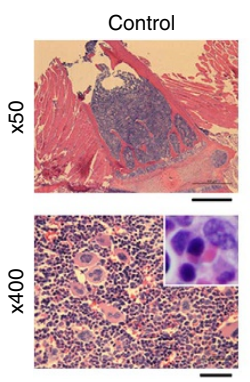
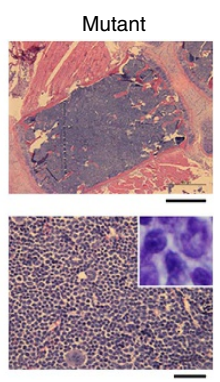
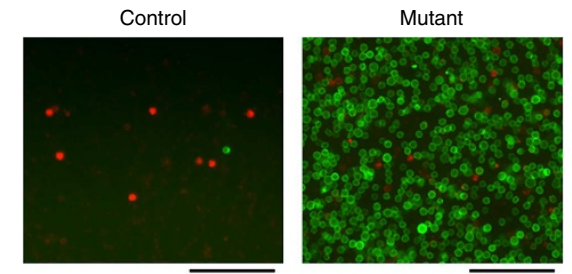

Figure 2 | Deletion of RBP-J in renin-lineage cells results in cell autonomous precursor B-cell leukaemia with infiltration of multiple organs. (a) MayGrunwald Giemsa-stained blood smears from control and mutant mice at low and high power. Scale bars equal $100 \mu \mathrm{m}$ (top row) and $20 \mu \mathrm{m}$ (bottom row). (b) Representative flow cytometric analysis of bone marrow. Control mice (left column) show $14.4 \%$ B cells with normal immunophenotype (B220 ${ }^{+}$

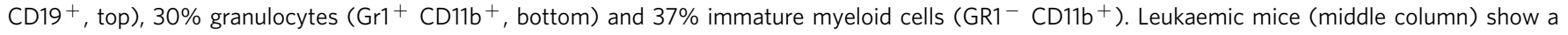
significant reduction in normal B cells (0.4\%), granulocytes (5.3\%) and immature myeloid cells (4.8\%), and a markedly expanded population of lymphoblasts (89\%) with aberrant dim B220 expression (B220 $\left.{ }^{\mathrm{Dim}} \mathrm{CD} 19^{+}\right)$. (c) Representative flow cytometric analysis of bone marrow from control and leukaemic mice demonstrating arrest of B-cell maturation. Control marrow contains $0.16 \%$ of common lymphocyte progenitors (Lin ${ }^{-}$IL7R $\alpha^{+}$) compared with $\sim 0 \%$ in leukaemic marrow (left column). Control marrow contains $2.6 \%$ of pro B cells $\left(B 220^{+} \mathrm{CD}_{4} 3^{+}\right.$) and $7 \%$ of $\mathrm{B} 22 \mathrm{O}^{+} \mathrm{CD} 43^{-} \mathrm{B}$ cells (middle), that correspond $43 \%$ to pre $B$ cells (B220 $\left.{ }^{+} \mathrm{CD}_{4} 3^{-} \operatorname{lgM}{ }^{-} \operatorname{lgD}{ }^{-}\right), 22 \%$ to immature $B$ cells $\left(B 220^{+} \mathrm{CD}_{4} 3^{-} \operatorname{lgM}{ }^{+} \operatorname{lgD}{ }^{-}\right.$) and $33 \%$ to mature $B$ cells $\left(\mathrm{B}_{22} \mathrm{O}^{+} \mathrm{CD} 43^{-} \mathrm{IgM}^{+} \mathrm{IgD}^{+}\right)$(right). The leukaemic marrow has a large population of $\mathrm{B}^{2} 2 \mathrm{O}^{+} \mathrm{CD} 43^{+}$cells (73\%) (middle) similar to a pro B-cell population, and minimal $\operatorname{lgM}$ or $\operatorname{lgD}$ expression marking the lymphoblasts as precursor B-cell leukaemia (right). (d) Haematoxylin and eosin staining of spleen sections from control and mutant mice. Scale bar, $500 \mu \mathrm{m}$. (e) Haematoxylin and eosin staining of liver sections from control and mutant mice. Scale bar, $100 \mu \mathrm{m}$. (f) Low and high magnification of bone marrow. Scale bar, $500 \mu \mathrm{m}$ (top row) and $50 \mu \mathrm{m}$ (bottom row). Insets show higher magnification of lymphoid cells (d-f). ( $(\mathbf{g})$ Fluorescence of peripheral blood from control and mutant mice with $\mathrm{mT} / \mathrm{mG}$ reporter demonstrates expansion of the GFP ${ }^{+}$-cell population in mutant mice. Scale bar, $100 \mu \mathrm{m}$.

manuscript, the leukaemic cell lines continue to be passaged, with one line currently beyond 25 passages, over 6 months (Fig. 3a,b). This cell line that expresses GFP (we bred mutant mice with $m$ T/ $m G$ reporter mice) was chosen for extended analysis in transplant and gene expression studies. Deletion of RBP-J in this cell line was confirmed by PCR. To test whether those leukaemic cells are transplantable, $\mathrm{GFP}^{+}$cells from the aforementioned colonies were injected into the tail vein of irradiated host animals. At 1 week post injection, recipient animals were killed and organs were collected. While irradiated recipients that did not receive leukaemic cell injections had severely hypoplastic bone marrow, animals that received injections of leukaemic cells had a nearly normocellular marrow almost entirely composed of transplanted $\mathrm{GFP}^{+}$leukaemic cells (Fig. 3c). Further, leukaemic cells infiltrated multiple other organs including the spleen, lung, kidney, thymus and gonads as determined by the presence of massive numbers of GFP ${ }^{+}$cells (Supplementary Fig. 4). Finally, $\mathrm{GFP}^{+}$leukaemic cells from the bone marrow of transplanted recipient animals were recovered and placed back into culture. The cells continue to grow in methycellulose, currently at passage 6 , demonstrating the aggressive and resilient nature of these cells (Fig. 3a). Together, these studies indicate that deletion of RBP-J in renin cells results in leukaemic transformation as evidenced by clinical assessment, histologic evaluation, flow cytometry analysis, immunoglobulin rearrangements, colony-forming assays and transplantation studies.

Renin cells in haematopoietic organs are precursor B cells. To investigate the cell of origin and identity of the renin-expressing cell in the bone marrow and spleen, we used several strategies. First, we employed lineage tracing: we crossed Ren $1^{\text {dcre/ }+}$ mice with $m T / m G$ reporter mice that after Cre-mediated recombination express GFP in cells that expressed renin ${ }^{12}$. Fluorescence imaging demonstrated GFP ${ }^{+}$cells from the renin lineage in the spleen (Fig. 4a) and bone marrow (Fig. 4b), confirming the presence of cells from the renin lineage within these haematopoietic organs. RT-PCR confirmed the presence of renin mRNA in the bone marrow from control mice (Supplementary Fig. 5a).

Next, we performed methylcellulose colony assays to define the conditions that would best permit the growth and expansion of renin-lineage cells. Cells from the bone marrow of Ren $1^{d c r e /+} ; m T / m G$ mice were cultured under conditions permissive of either myeloid-erythroid or B-lymphocyte growth: cells from the renin lineage $\left(\mathrm{GFP}^{+}\right.$cells) had a growth advantage in 
a

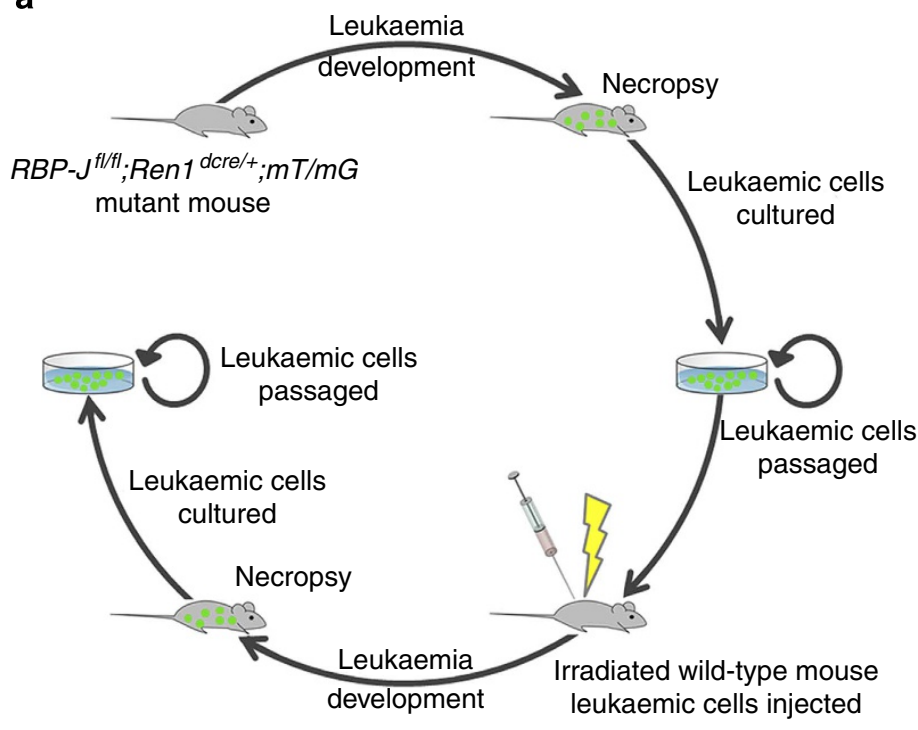

b

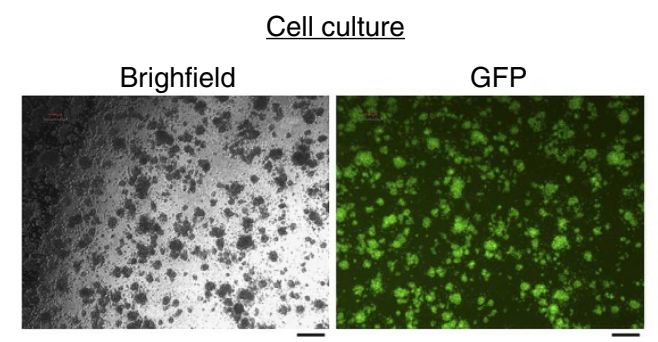

C

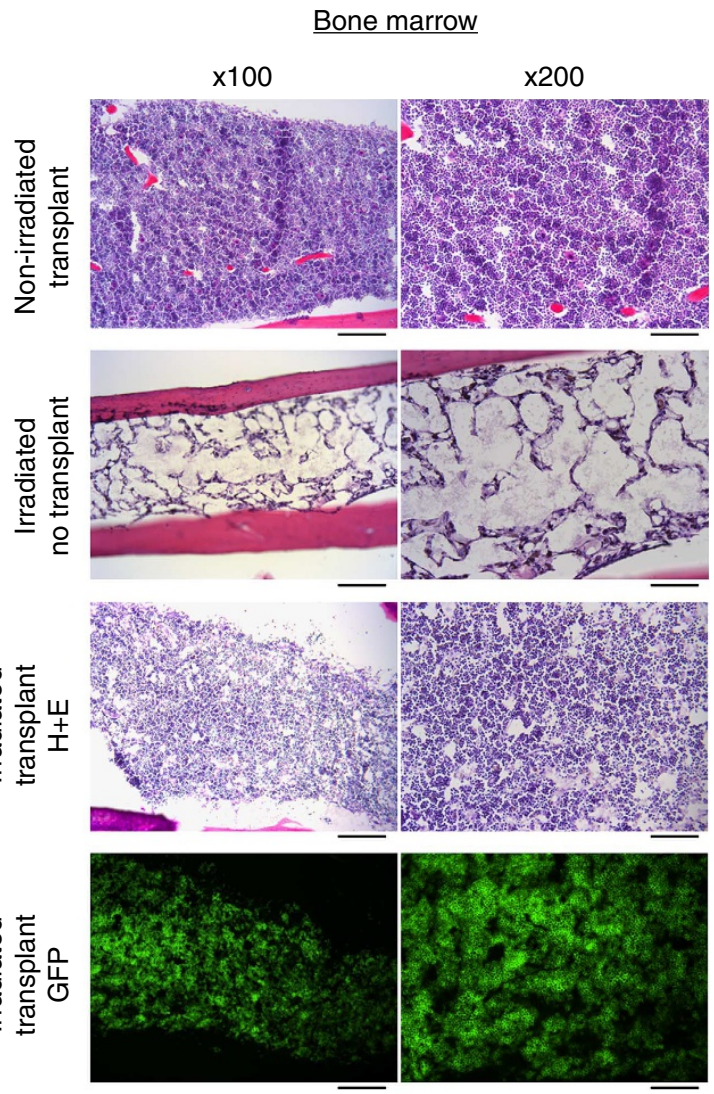

Figure 3 | Leukaemic cells grow in culture and are transplantable into irradiated mice. (a) Mutant animals expressing GFP $\left(R B P-f^{f l / f l} ; R e n{ }^{d c r e} /+{ }_{;} m T m G\right)$ developed leukaemia as described. When animals became moribund, necropsy was performed and bone marrow cells were collected for culture in methylcellulose. Cultured leukaemic cells are GFP ${ }^{+}$, have deletion of RBP-J, have gene expression patterns similar to leukaemic spleens and can be serially passaged over many months. Leukaemic cells from culture were then injected into irradiated wild-type mice with engraftment and infiltration of GFP ${ }^{+}$ leukaemic cells. Bone marrow cells were recovered from transplanted animals and continued to grow in methylcellulose culture. (b) Leukaemic cells grow as colonies in methylcellulose culture. The population of leukaemic cells is homogenous. Scale bar, $200 \mu \mathrm{m}$. (c) In non-irradiated mice, leukaemic cells failed to engraft following intravenous injection. These animals had normocellular bone marrow (top row) and almost no presence of GFP + cells ( 0 to 4 $\mathrm{GFP}^{+}$cells per bone marrow section). Irradiated animals that received only injection of vehicle control (media) had markedly hypocellular bone marrow (second row) and absence of GFP ${ }^{+}$cells. Animals that received irradiation and injection of leukaemic cells had a mildly hypocellular bone marrow (third row) with almost all of the marrow cells expressing GFP (bottom row) demonstrating engraftment of leukaemic cells $(n=3$ ). Scale bar, 200 $\mu$ m (left column) and $100 \mu \mathrm{m}$ (right column).

B-cell media versus myeloid-erythroid media suggesting again that renin-lineage cells are mostly B cells (Supplementary Fig. 5b-d). We also observed GFP ${ }^{+}$GEMM colonies in the myeloid-erythroid medium suggesting that a small number of renin precursors have myeloid potential and may be responsible for the less frequent myeloproliferative disorder we observed in a small proportion of the animals.

To determine the immunophenotype of renin cells within the bone marrow, we performed flow cytometry. Bone marrow cells from $\operatorname{Ren}^{c}$-YFP (YFP labels cells actively transcribing renin) ${ }^{14}$ and Ren $1^{\text {dcre/ }+} ; m T / m G$ mice (GFP labels cells, which throughout their history have expressed or continue to express renin) were obtained and stained for lineage markers of B lymphocytes, $\mathrm{T}$ lymphocytes and myeloid cells and analyzed by flow cytometry. These studies demonstrated that the large majority of marrow cells that either actively express renin ( $\mathrm{YFP}^{+}$cells) or are descendants from the renin-producing cells $\left(\mathrm{GFP}^{+}\right.$cells) express markers of $\mathrm{B}$ cells (B220, CD19, IgM) with reduced expression of myeloid (Gr1 and CD11b) or T-cell (CD3) markers (Fig. 4c,d). YFP ${ }^{+}$cells had $<10 \%$ IgM expression suggesting that renin expression occurs in early B-lymphocyte progenitors, whereas $\mathrm{GFP}^{+}$cells had $\sim 60 \%$
IgM expression reflecting the normal maturation of renin-expressing $\mathrm{B}$-lineage cells within the bone marrow. In both sets of experiments, the $\mathrm{YFP}^{-}$and $\mathrm{GFP}^{-}$cells represented a normal distribution of wild-type bone marrow (Fig. 4e).

Additional flow strategies were performed to determine the stage of development of renin-expressing and renin-lineage cells. We quantified the number of common lymphocyte progenitors $\left(\mathrm{Lin}^{-} \mathrm{IL7R}^{+}\right)$, Pro-B cells $\left(\mathrm{B} 220^{+} \mathrm{CD} 43^{+}\right)$, Pre-B cells $\left(\mathrm{B} 220^{+} \mathrm{IgM}^{-} \mathrm{IgD}^{-}\right)$, Immature B-cells $\left(\mathrm{B} 220^{+} \mathrm{IgM}^{+} \mathrm{IgD}^{-}\right)$,

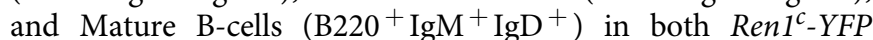
and Ren $1^{d c r e /+} ; m T / m G$ mice (Fig. 4f). Further, we investigated the classically defined B-cell developmental subsets in the bone marrow (Hardy fractions $\mathrm{A}-\mathrm{F})^{15}$ and found that renin is expressed mostly by Fraction B cells (Supplementary Fig. 6). Collectively, these studies demonstrated that cells that are actively expressing renin are Pro-B cells, while renin-lineage cells, as expected, encompass premature, immature and mature B cells (Fig. 4f and Supplementary Table 1).

Given that RBP-J deletion occurs in B cells that currently express or previously expressed renin (provisionally, we denominated this cell as ' $\mathrm{B}^{\text {renin}}$-cell'), we determined the relative 
contribution of renin-expressing cells to the cell endowment of the bone marrow and spleen at different developmental stages. We sorted cells currently expressing renin $\left(\mathrm{YFP}^{+}\right)$and cells from the renin-lineage $\left(\mathrm{GFP}^{+}\right)$isolated from the bone marrow and spleen of Ren $1^{c}-Y F P$ and Ren $1^{d c r e /{ }^{+}} ; m T / m G$ mice described above. The fraction of renin-expressing and renin-lineage cells decreases with age both in the bone marrow and spleen (Fig. 4g,h). Thus, renin cells constitute a distinct subset of the total B-lymphocyte population, and their numbers diminish with age.
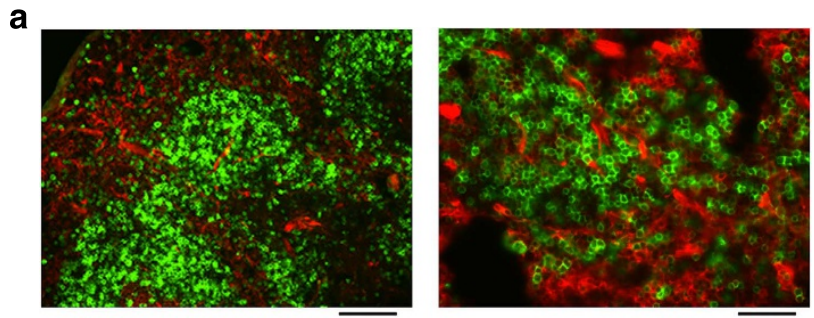

c
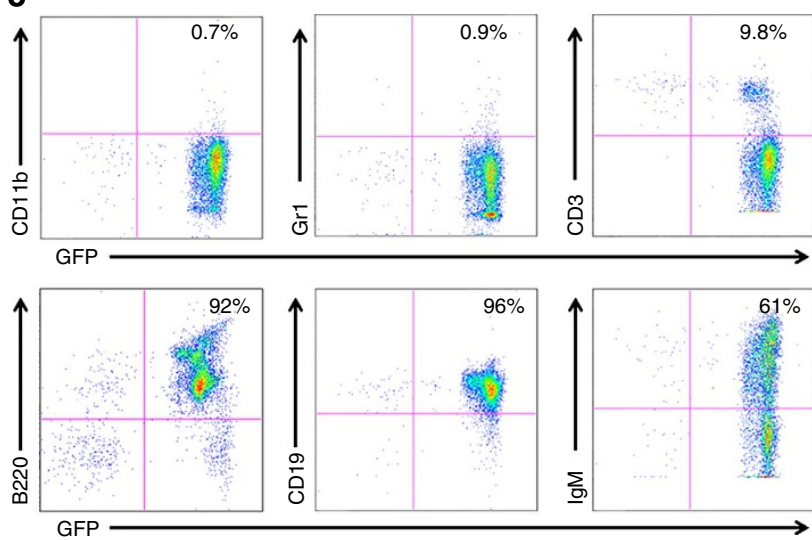

e
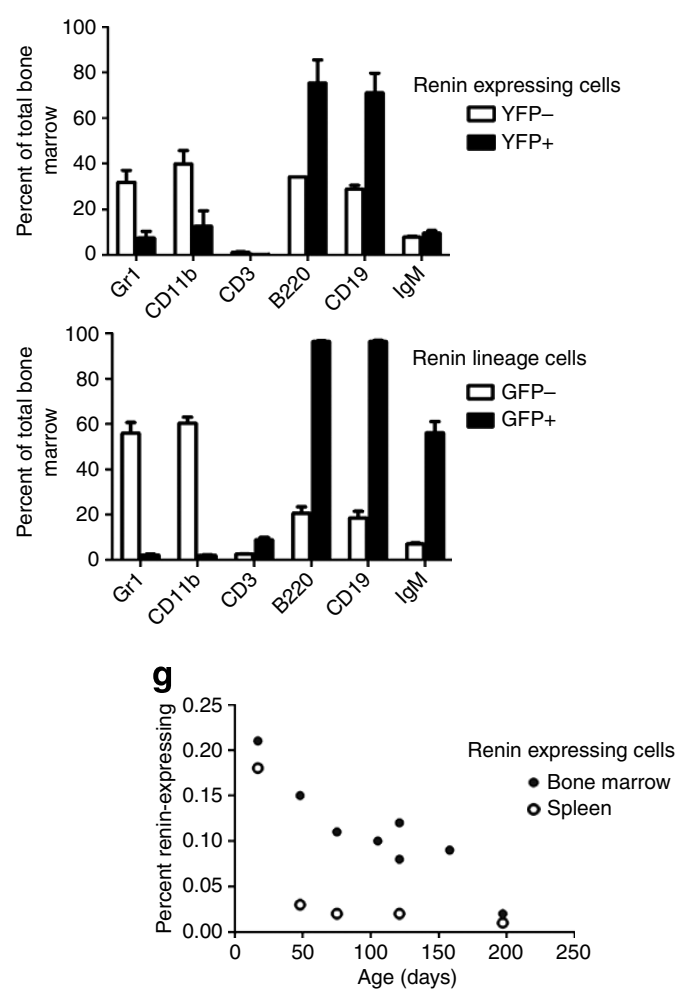

Given the high percentage of renin-lineage cells in the spleen ( $\sim 25 \%$ shortly after birth), we performed multiple experiments to further characterize the identity and stage of maturation of these cells. First, we collected spleens of Ren $1^{\text {dcrel }}+; m T / m G$ reporter mice, stained sections with IgM antibody and evaluated by immunofluorescence. These studies demonstrated that GFP ${ }^{+}$ cells in the spleen (renin-lineage) are predominantly located in the follicles, and that they represent both marginal zone (IgM bright) and follicular (IgM dim) B cells (Fig. 5a). Further, splenic $\mathrm{B}$ cells from Ren1 $1^{\text {dcre }}+{ }_{+} ; m T / m G$ mice were analysed by flow

b
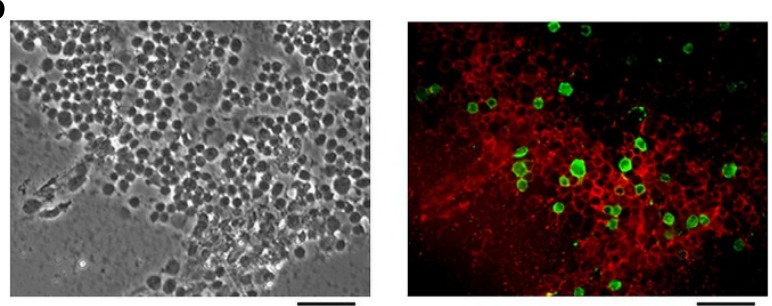

d
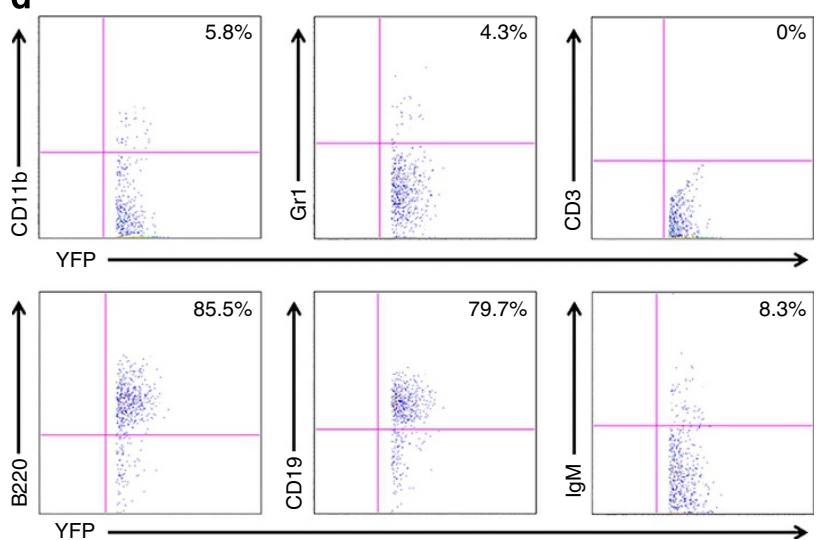

$\mathbf{f}$
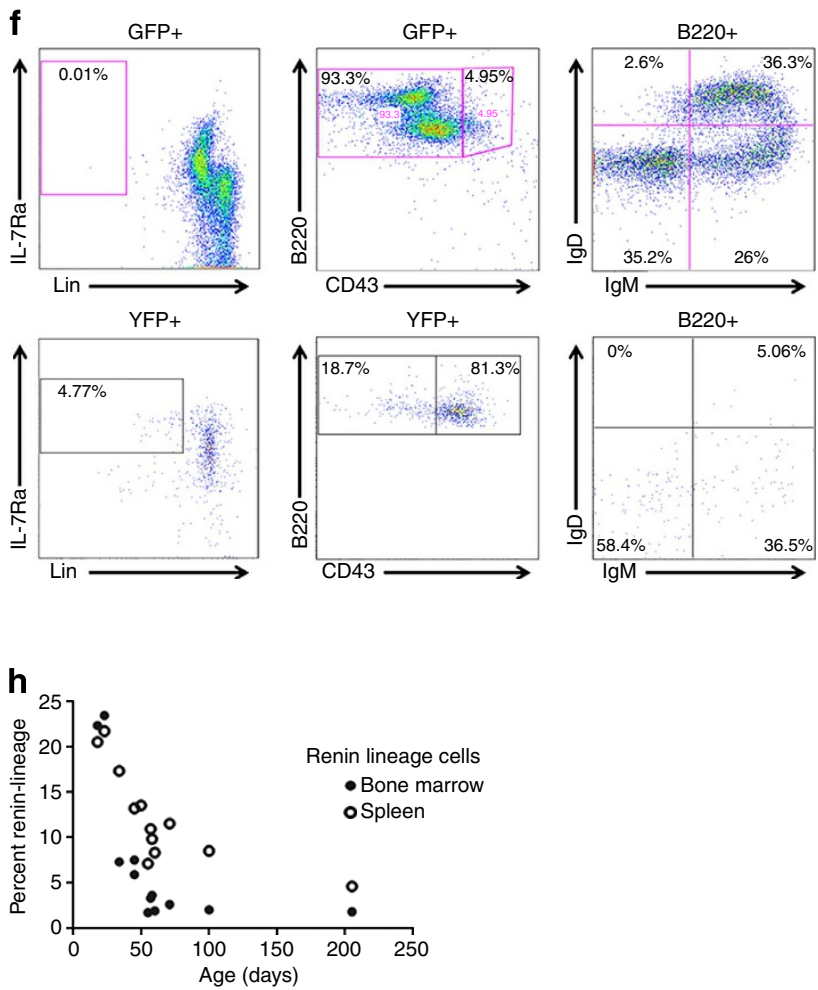
cytometry for expression of B220, CD21 and CD23. We found that $\mathrm{GFP}^{+}$cells in the spleen include both marginal zone $\left(\mathrm{B} 220^{+} / \mathrm{CD} 21^{\mathrm{Hi}} / \mathrm{CD} 23^{\mathrm{Lo}}\right)$ and follicular $\left(\mathrm{B} 220^{+} / \mathrm{CD} 21^{\mathrm{Int}} /\right.$ $\mathrm{CD} 23^{\mathrm{Hi}}$ ) B cells (Fig. 5b), and further confirmed by staining with $\mathrm{B} 220$, IgM and $\operatorname{IgD}$ that $\mathrm{GFP}^{+}$cells mark both marginal zone $\left(\operatorname{IgM}^{\mathrm{Hi}} / \operatorname{IgD}^{\mathrm{Lo}}\right)$ and follicular (IgM $\left.{ }^{\mathrm{Lo}} / \operatorname{IgD}^{\mathrm{Hi}}\right) \mathrm{B}$ cells (Fig. $5 \mathrm{c}$ ).

Next, to define whether $\mathrm{B}^{\text {renin }}$-cells respond to a decrease in angiotensin II as the classical kidney renin cells, we treated a

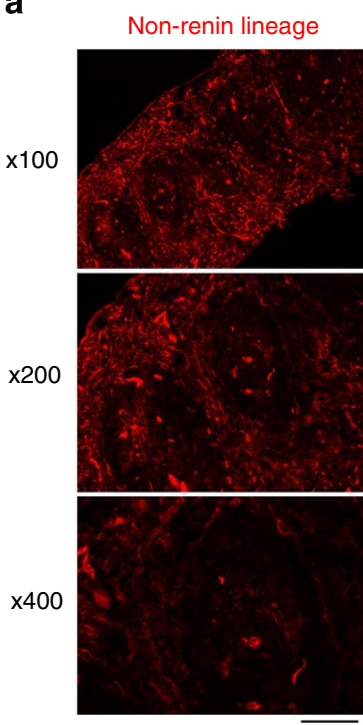

b

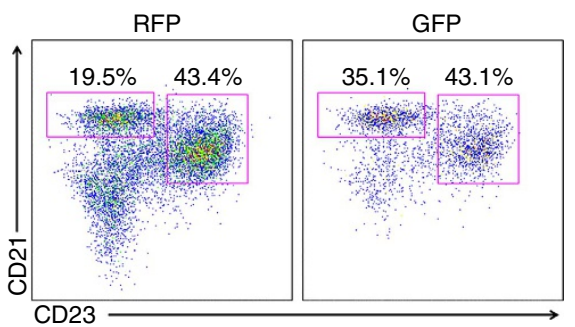

Renin lineage
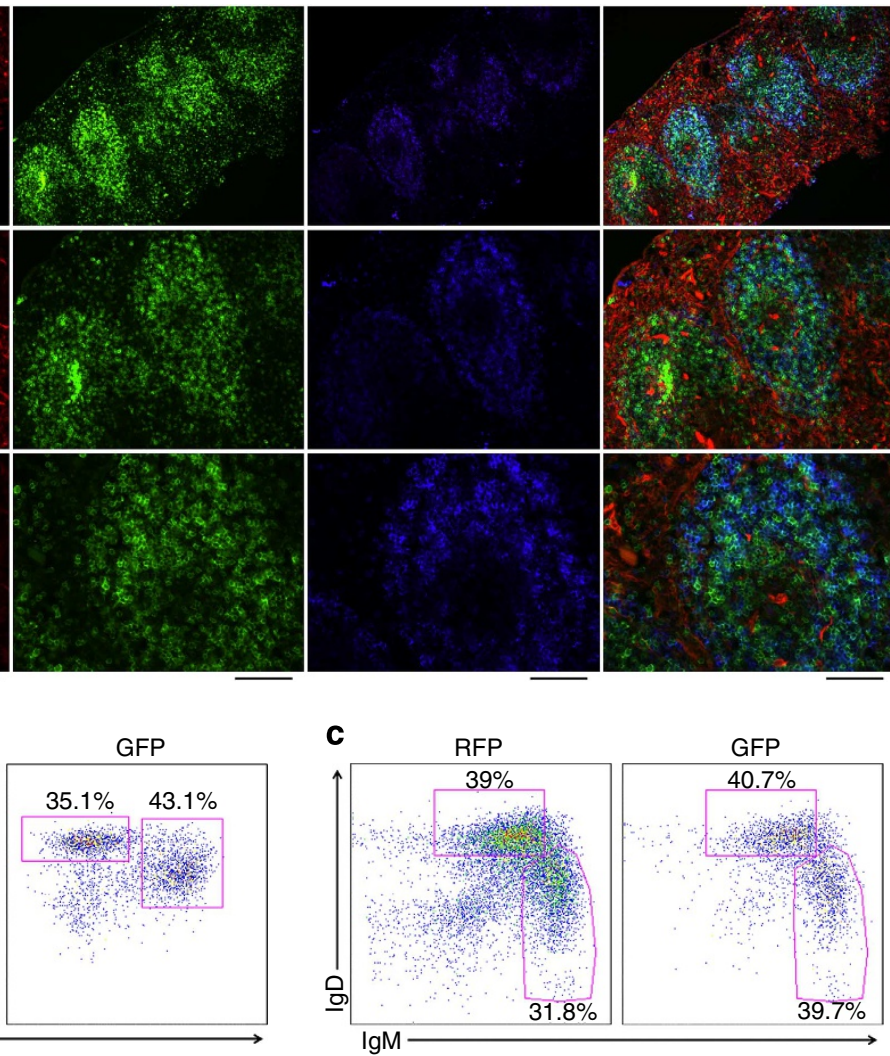

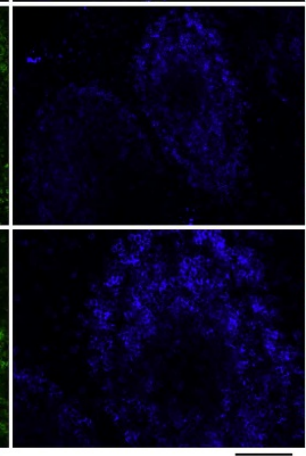

$\lg \mathrm{M}$
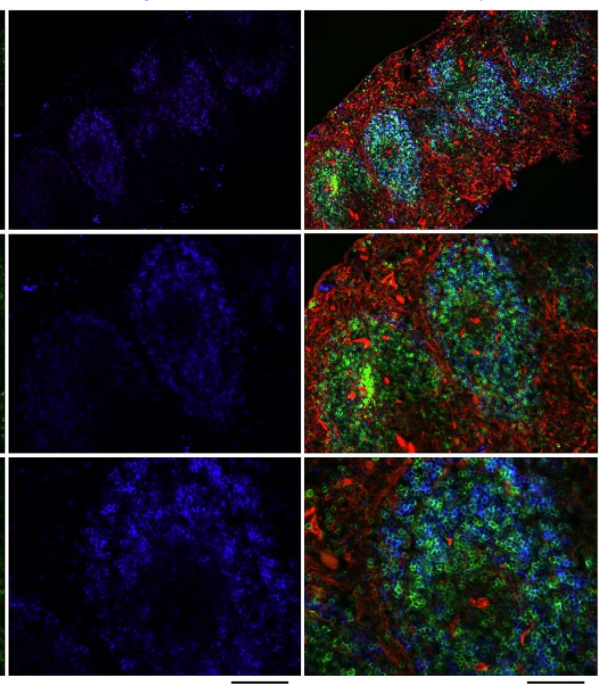

$9.7 \%$

Figure 5 | Renin cells in the spleen represent both marginal zone and follicular B cells. (a) Fluorescence images of spleens from Ren $7^{d c r e / ~}+; m T / m G$ mice. GFP ${ }^{+}$cells (renin-lineage) localize to the follicles of the spleen and largely co-localize with lgM. Scale bar, $200 \mu \mathrm{m}$ (top row), $100 \mu \mathrm{m}$ (middle row) and $50 \mu \mathrm{m}$ (bottom row). (b) Flow cytometry on splenocytes from Ren1dcre/ $+; m T / m G$ mice demonstrating that renin-lineage cells (GFP ${ }^{+}$) express cell surface antigens consistent with both marginal zone $\left(\mathrm{CD} 21^{\mathrm{Hi}} \mathrm{CD} 23^{-}\right)$and follicular $\left(\mathrm{CD} 21^{\operatorname{lnt}} \mathrm{CD} 23^{+}\right) \mathrm{B}$ cells (gates are on $\mathrm{B} 220+$ cells). (c) Flow cytometry on spleen cells from Ren $1^{d c r e /+} ; m T / m G$ mice confirming that renin-lineage cells $\left(\mathrm{GFP}^{+}\right.$) express cell surface antigens consistent with both marginal zone $\left(\operatorname{IgM}^{\mathrm{Hi}} \mathrm{IgD}{ }^{\mathrm{Lo}}\right)$ and follicular $\left(\lg \mathrm{M}^{\mathrm{LO}} \mathrm{IgD} \mathrm{Hi}^{\mathrm{Hi}}\right) \mathrm{B}$ cells (gates are on $\mathrm{B} 220+$ cells).

Figure 4 | Renin cells represent a small and diminishing population of B lymphocytes. (a) Low (left) and high (right) magnification fluorescence images of spleens from Ren1dcre/,$+ m T / m G$ mice. Scale bar, $100 \mu \mathrm{m}$ (left) and $50 \mu \mathrm{m}$ (right). (b) Bright-field (left) and fluorescence (right) images of the bone marrow from Ren ${ }^{d c r e /+} ; m T / m G$ mice showing the presence of GFP ${ }^{+}$renin-lineage cells. Scale bar, $50 \mu m$. (c) Representative flow cytometry on the bone marrow from Ren1 $7^{d c r e} /+, m T / m G$ mice demonstrating that renin-lineage cells (GFP ${ }^{+}$) express cell surface antigens most consistent with B cells $\left(92 \% \mathrm{~B}_{2} 20^{+}, 96 \% \mathrm{CD} 19^{+}\right.$and $\left.61 \% \mathrm{IgM}^{+}\right)$with minimal staining for markers of myeloid $\left(<1 \% \mathrm{CD} 11 \mathrm{~b}^{+}\right.$and $\left.\mathrm{Gr}^{+}\right)$and $\left.\mathrm{T}^{(<10 \%} \mathrm{CD} 3^{+}\right)$cells. (d) Representative flow cytometry on bone marrow from Ren $7^{c}$-YFP transgenic mice demonstrating that renin-expressing cells (YFP ${ }^{+}$) are precursor

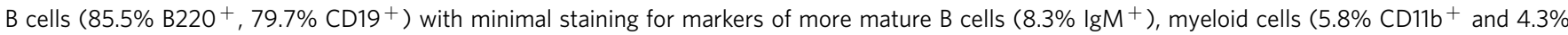
$\mathrm{Gr}^{+}$) and T cells $\left(0 \% \mathrm{CD}^{+}\right)$. (e) A comparison of YFP ${ }^{-}$versus YFP ${ }^{+}$(top) and $\mathrm{GFP}^{-}$versus GFP ${ }^{+}$(bottom) cell immunophenotypes in the bone marrow of Ren $7^{c}-$ YFP and Ren $7^{d c r e /+} ; m T / m G$ reporter mice. Error bars represent s.e.m. $\left(n=2\right.$ for renin-expressing $\left(\right.$ Ren $\left.7^{c}-Y F P\right)$ experiments and $n=4$ for renin-lineage (Ren $\left.1^{d c r e /+} ; m T / m G\right)$ experiments). (f) Top panel: renin-lineage cells from the bone marrow were evaluated for cell surface markers

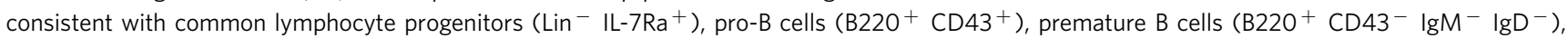
immature $\mathrm{B}$ cells $\left(\mathrm{B} 22 \mathrm{O}^{+} \mathrm{CD}^{-} 3^{-} \mathrm{IgM} \mathrm{g}^{+} \mathrm{IgD}{ }^{-}\right)$and mature $\mathrm{B}$ cells $\left(\mathrm{B} 22 \mathrm{O}^{+} \mathrm{CD} 43^{-} \mathrm{IgM} \mathrm{g}^{+} \mathrm{IgD}{ }^{+}\right)$. This strategy demonstrated that renin-lineage cells are $\sim 0.01 \%$ common lymphocyte progenitors, $<5 \%$ pro-B cells, $\sim 33 \%$ premature B cells, $\sim 24 \%$ immature B cells, and $\sim 34 \%$ mature B cells. Bottom panel: renin-expressing cells were evaluated using the same strategy. This demonstrated that renin-expressing cells are predominantly (81.3\%) pro-B cells with smaller populations of common lymphocyte progenitors $(4.77 \%)$, pre-B cells $(10.9 \%)$, immature B cells $(6.8 \%)$ and mature B cells $(0.95 \%)$. Images are representative of experiments performed in triplicate. ( $(\mathbf{g})$ The percentage of renin-expressing (YFP ${ }^{+}$) cells within the bone marrow and spleen was quantitated over time using Ren $7^{C}$-YFP mice and flow cytometry. Shortly, after birth, mice had $\sim 0.2 \%$ renin-expressing cells. However, this percentage decreased with age in both the spleen and marrow to $\sim 0.01 \% . n=8$ for bone marrow samples and $n=5$ for spleen samples. (h) The percentage of renin-lineage $\left(\mathrm{GFP}^{+}\right)$cells within the bone marrow and spleen of Ren1dcre/,$+ m T / m G$ mice as measured by flow cytometry. The percentage of renin-lineage cells decreases from $\sim 20 \%$ shortly after birth to $\sim 2 \%$ at 200 days of life in the bone marrow. $n=12$ for both bone marrow and spleen samples. 
Bac-ren-GFP mice ${ }^{16}$ (here GFP identifies cells currently synthesizing renin) with the angiotensin-converting enzyme inhibitor captopril and observed by flow cytometry a 2.5 -fold increase in the percentage of renin-expressing cells in the bone marrow (Supplementary Fig. 7a). Similarly, mice with deletion of the Ren $1^{d}$ gene $\left(\right.$ Ren $\left.1^{d c r e / c r e} ; m T / m G\right)$ showed an increase in the number of circulating $\mathrm{GFP}^{+}$cells (Supplementary Fig. 7b), suggesting a recruitment of renin progenitors and their descendants both in the bone marrow and the circulation.

Finally, we performed microarray analysis on renin-expressing cells sorted from the bone marrow isolated from Bac-ren-GFP mice. In addition to high expression of renin (53-fold enrichment when corrected for presorted cells), these cells displayed high expression of transcripts characteristic of precursor B lymphocytes including early B-cell factor (Ebf1, 13.9-fold), immunoglobulin lambda chain variable 1 (Iglv1, 13.8-fold), recombination-activating gene 1 (Rag1, 7.0-fold), pre-B-lymphocyte gene 3 (Vpreb3, 5.6-fold) and numerous other lymphocytespecific transcripts displayed in abbreviated form in Table 1. Thus, in agreement with the lineage tracing, colony-forming capacity and immunophenotyping, the microarray analysis indicated that normal renin-expressing cells in the bone marrow, the cells of origin for this type of lymphoid leukaemia, are B-lymphocyte progenitors.
$R B P-J$ deletion in renin cells enriches a B-cell gene programme. We next investigated how deletion of RBP-J in renin-lineage cells affects the molecular programmes regulating lymphopoiesis and contributes to leukaemogenesis. Given that the spleens of mice

\begin{tabular}{|c|c|c|c|}
\hline $\begin{array}{l}\text { Top genes } \\
\text { Up }\end{array}$ & $\begin{array}{c}\text { Fold } \\
\text { change }\end{array}$ & Symbol & Gene name \\
\hline 2 & 53.6 & $\begin{array}{l}\text { Ren1/ } \\
\operatorname{Ren} 2\end{array}$ & Renin \\
\hline 21 & 13.9 & Ebf1 & Early B-cell factor 1 \\
\hline 22 & 13.8 & $\lg / v 1$ & $\begin{array}{l}\text { Immunoglobulin lambda chain, } \\
\text { Variable } 1\end{array}$ \\
\hline 49 & 10.8 & Foxo1 & Forkhead Box 01 \\
\hline 161 & 7.1 & Sox4 & SRY-box containing gene 4 \\
\hline 173 & 7.0 & Ikzf3 & IKAROS family zinc family 3 \\
\hline 175 & 7.0 & Rag1 & Recombination activating gene 1 \\
\hline 197 & 6.7 & Dtx1 & Deltex 1 homologue \\
\hline 304 & 5.6 & Vpreb3 & Pre-B-lymphocyte gene 3 \\
\hline 355 & 5.2 & Pax5 & Paired box gene 5 \\
\hline 605 & 4.0 & Rag2 & Recombination-aActivating gene 2 \\
\hline 1024 & 3.1 & Raglap1 & Rag1 activating protein 1 \\
\hline
\end{tabular}

Table 2 | Enrichment of a B-cell gene programme and epigenetic changes in leukaemic spleens.

\begin{tabular}{|c|c|c|c|c|}
\hline $\begin{array}{l}\text { Fold } \\
\text { change }\end{array}$ & Symbol & Gene name & $\begin{array}{c}\text { Mutant versus control } \\
\text { H3K4me3 }\end{array}$ & $\begin{array}{r}\text { Mutant versus } \\
\text { H3K27me }\end{array}$ \\
\hline \multicolumn{5}{|c|}{ Upregulated genes } \\
\hline 44.4 & $\lg \mid 17$ & Immunoglobulin lambda-like polypeptide 1 & 50.903 & 0.400 \\
\hline 27.3 & Enpep & Glutamyl aminopeptidase & 32.289 & 0.446 \\
\hline 11.9 & Rag1 & Recombination-activating gene 1 & 15.310 & 0.898 \\
\hline 10.3 & Vpreb1 & Pre-B-lymphocyte gene 1 & $68.980^{\ddagger}$ & 0.587 \\
\hline 9.9 & Rag2 & Recombination-activating gene 2 & 7.970 & 0.455 \\
\hline 6.9 & Vpreb3 & Pre-B-lymphocyte gene 3 & 5.729 & 0.948 \\
\hline 4.5 & Gpam & glycerol-3-phosphate acyltransferase, mitochondrial & 1.414 & 1.376 \\
\hline 4.2 & Erg & $\begin{array}{l}\text { Avian erythroblastosis virus } E \text { - } 26 \text { ( } v \text {-ets) oncogene } \\
\text { related }\end{array}$ & 0.742 & 0.887 \\
\hline 3.9 & Cd93 & CD93 Antigen & 5.928 & 0.307 \\
\hline 3.9 & Atp1b1 & ATPase, $\mathrm{Na}+/ \mathrm{K}+$ transporting, beta 1 polypeptide & 1.448 & 0.648 \\
\hline 4.0 & Sox4 & SRY-box containing gene 4 & 1.547 & 1.249 \\
\hline 3.4 & Ppmle & Protein phosphatase $1 E$ (PP2C domain containing) & 2.047 & 0.450 \\
\hline 3.4 & Eps8 & Epidermal growth factor receptor pathway substrate 8 & 2.289 & 0.565 \\
\hline 2.6 & Myb & Myeloblastosis oncogene & 1.947 & 0.486 \\
\hline 2.2 & Ebf1 & Early B-cell factor 1 & 1.280 & 0.619 \\
\hline 1.7 & $E 2 A$ & Transcription Factor E2A (Tcf3) & 1.740 & 1.337 \\
\hline
\end{tabular}

Downregulated genes

$\begin{array}{lllll}5.3 & \text { Cd7 } & \text { CD7 antigen } & 0.117 & 1.379 \\ 4.1 & \text { Ccr9 } & \text { Chemokine (C-C motif) receptor 9 } & 0.897 & 1.520 \\ 4.0 & \text { Art2b } & \text { ADP-ribosyltransferase 2b } & 0.109 & 1.056 \\ 4.0 & \text { Faim3 } & \text { Fas apoptotic inhibitory molecule 3 } & 0.191 & 1.880 \\ 3.9 & \text { Dtx1 } & \text { Deltex 1 homologue } & 0.101 & 4.086 \\ 3.8 & \text { Ctsw } & \text { Cathepsin W } & 0.227 & 0.948 \\ 3.6 & \text { Cr2 } & \text { Complement receptor 2 } & 0.677 & 0.623 \\ 3.5 & \text { Tcf7 } & \text { Transcription factor 7, T-cell specific } & 0.198 & 1.802 \\ 2.8 & \text { Cd4 } & \text { CD4 antigen } & 0.096 & 1.259 \\ 2.8 & \text { Lat } & \text { Linker for activation of T cells } & 0.243 & 1.706 \\ 2.8 & \text { Icos1 } & \text { icos ligand } & 0.188 & 6.590 \\ 2.5 & \text { Tbx21 } & \text { T-box 21 } & 0.119 & 1.516 \\ 2.4 & \text { Runx3 } & \text { Runt-related transcription factor 3 } & 0.093 & 2.615\end{array}$

The H3K4me3 mutant versus control ratio was determined using the average fragment density over the promoter $(-2,500$ bp to $+2,500$ bp relative to the transcription start)

$\dagger$ The H3K27me3 mutant versus control ratio was determined using the average fragment density over the gene body and flanking regions (the gene region plus 2,500 bp upstream to 5,000 bp downstream).

$\ddagger$ For Vpreb1 the H3K4me3 average fragment density is limited to $-500 \mathrm{bp}$ to $+500 \mathrm{bp}$ relative to the transcription start to discriminate the Vpreb1 signal from that of the nearby gene, Top3b. 
with leukaemia were enlarged over 15 -fold due to massive infiltration with leukaemic cells, we performed microarray analysis on RNA isolated from whole spleens of control and leukaemic mice. In mice with B-cell leukaemia, genes involved in growth and differentiation of early lineage B cells (Ebf1, Sox4), immunoglobulin gene rearrangements (Vpreb1, Igll1, Rag1, Rag2) or cell division $(M y b)$ were markedly upregulated (Table 2), whereas genes that either control or are characteristic of $\mathrm{T}$ lymphocytes (Tcf7, Tbx21, Art2b, CD4, CD7, Ccr9) were repressed when compared with control mice (Table 2). We validated the mRNA expression levels for these genes by quantitative RT-PCR (qRT-PCR) and found that the qRT-PCR and microarray data expression profiles were highly correlated (Fig. 6a,b). In the mutant, the levels of Igll1, Enpep, Rag1, Vpreb1 and Vpreb3 as measured by qRT-PCR were even more elevated (1,410-, 73-, 59-,
1,131- and 13-fold, respectively) than in the microarray array data, suggesting that the microarray detection had reached saturation for these transcripts. Further, we performed qRT-PCR from a pure population of cultured $\mathrm{GFP}^{+}$leukaemic cells and found a similar pattern of upregulation of genes marking early B-cell development including VpreB1, Igll1 and VpreB3 (Supplementary Fig. 8).

To obtain a comprehensive view of the changes in the chromatin landscape in the leukaemic cells, we performed genome-wide ChIP-Seq analysis of chromatin from whole spleens of control and leukaemic mice using antibodies against H3K4me3 (a marker of gene activation) and $\mathrm{H} 3 \mathrm{~K} 27 \mathrm{me} 3$ (a marker of gene suppression). There was remarkable congruence between this ChIP-Seq data and the mRNA array data. Table 2 shows the ratios of the average fragment density (Mutant versus Control) a
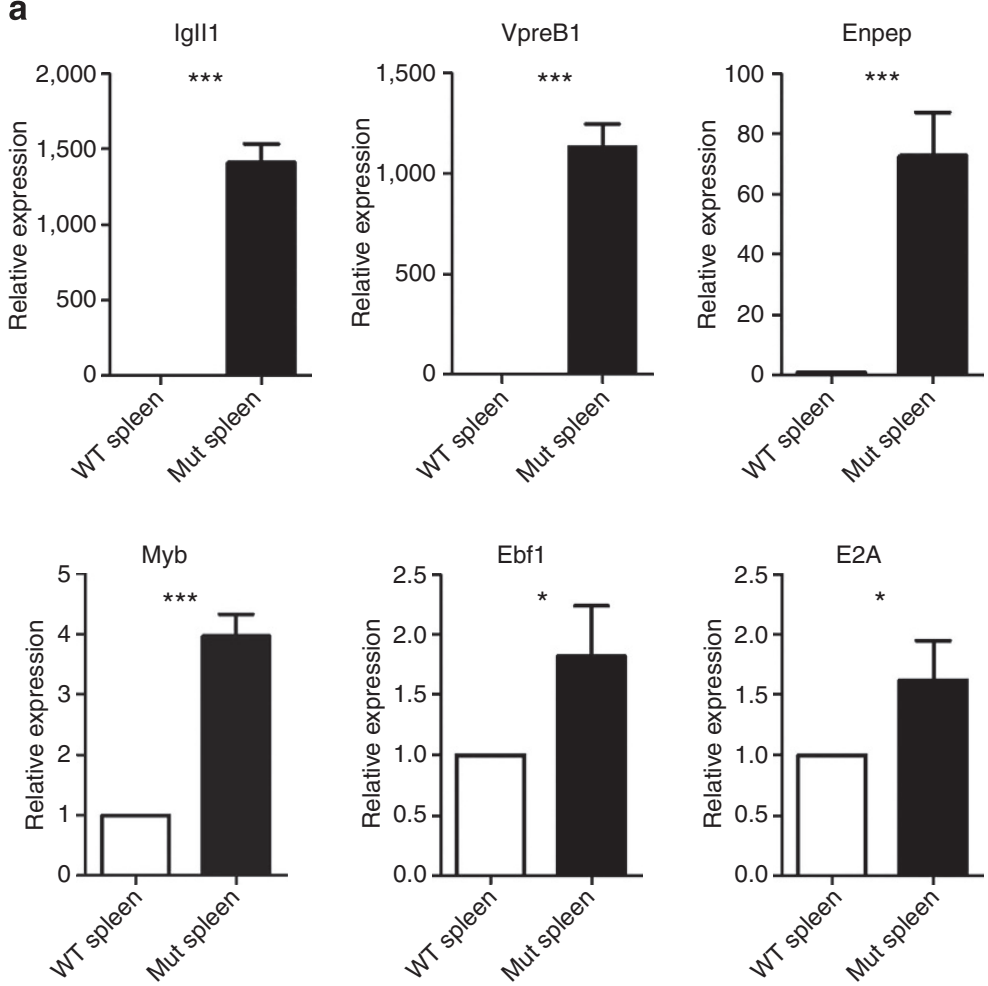
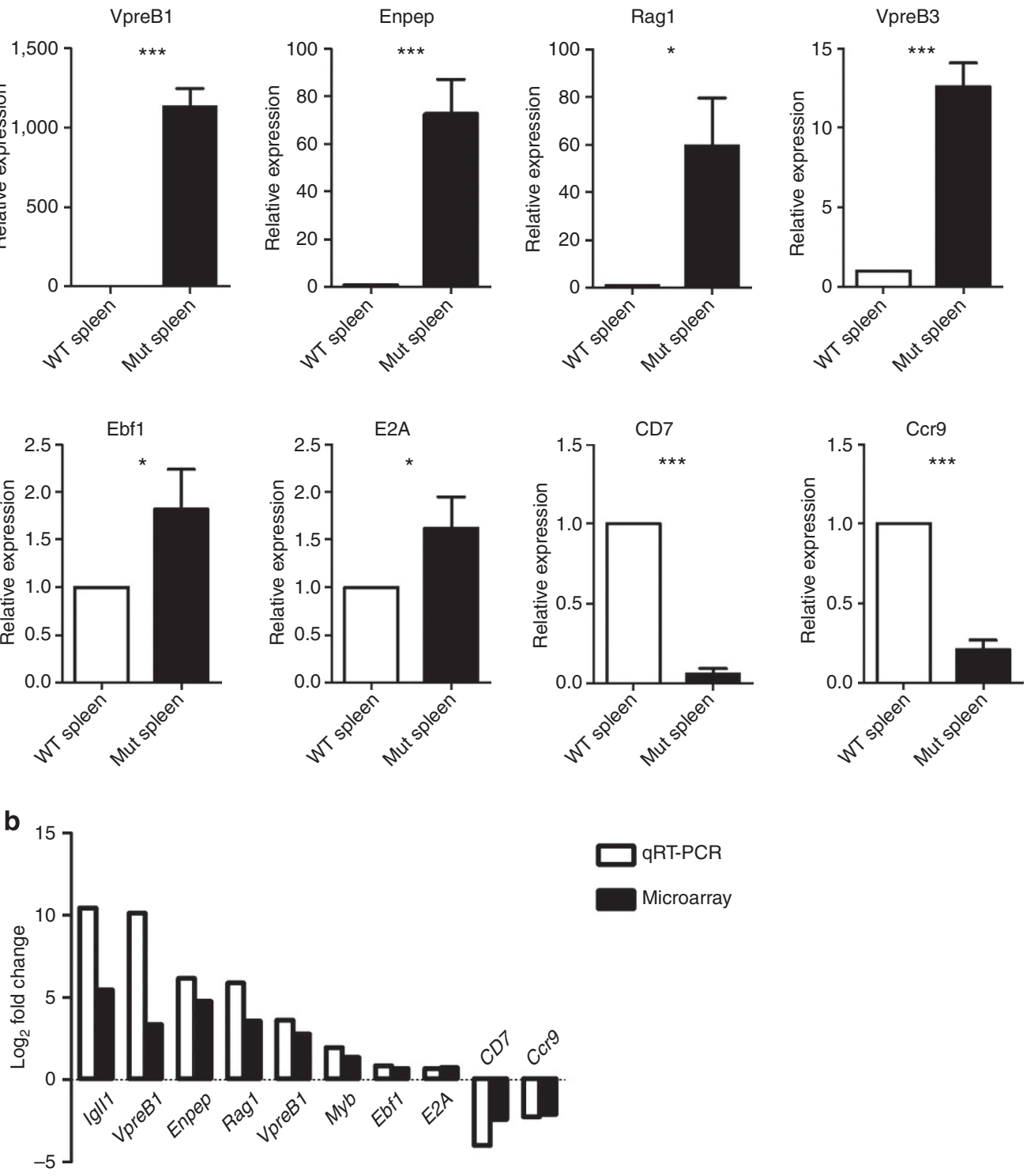

Figure 6 | Deletion of $\boldsymbol{R B P}$-J in renin-expressing haematopoietic precursors enriches the B-cell genetic programme. (a) Validation by $q R T-P C R$ of the differentially expressed genes in RNA from control and mutant spleens. Genes involved in early B-cell development and in T-cell and NK-cell commitment showed a remarkable difference in expression between mutant and control spleens. Error bars are s.e.m. $(n=5$ for each condition). Student's $t$-test ${ }^{\star} P<0.05$; ${ }^{\star \star \star} P<0.001$. (b) Log2 values of fold changes in gene expression as measured by qRT-PCR and microarray analyses. The expression profiles were highly similar between qRT-PCR and microarray data. Igll1 and VpreB1 levels in the mutants are substantially higher by qRT-PCR measurements than in the array, which is likely due to the saturation of the signal in the array. 


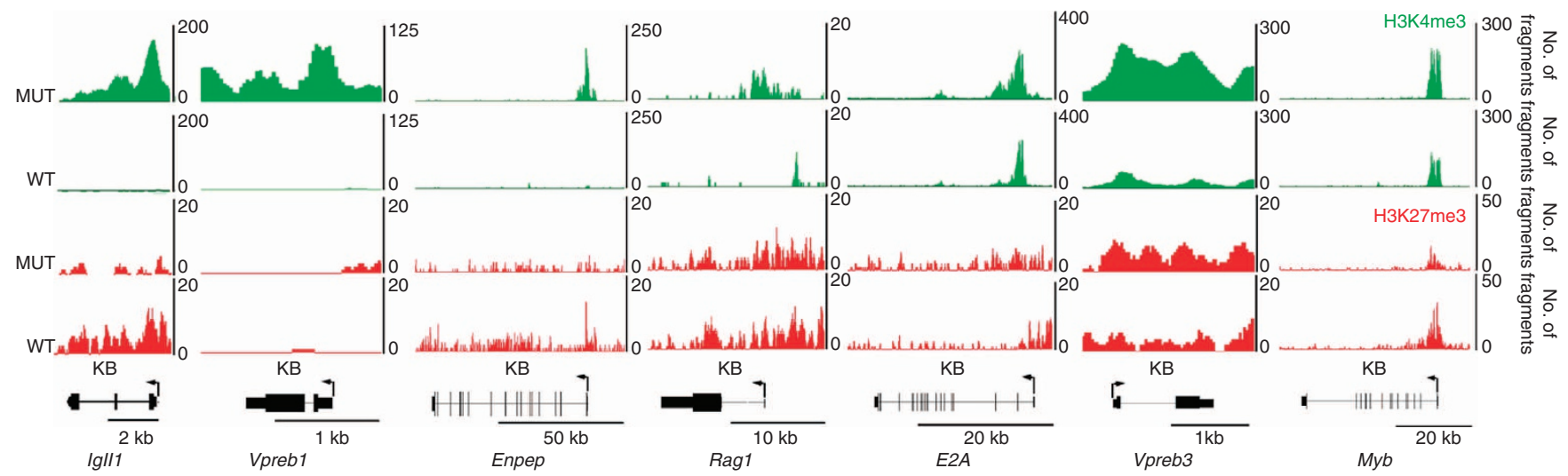

Figure 7 | Chromatin profiles of genes activated in the mutant leukaemic spleen. The profiles depict the ChIP-Seq signals for H3K4me3 (green) and H3K27me3 (red) modifications in mutant (MUT) and wild-type (WT) spleens. The $x$ axis for all genes is in KB with the scale indicated by the bar below each gene. The $y$ axis corresponds to the number of sequenced ChIP fragments that overlap a given position. The highly upregulated genes in the mutant all display increased occupancy of the H3K4me3 activation mark on the promoter and, in the case of Vprebl, Vpreb3 and Igll1, throughout the gene. In contrast, in the WT those genes have low or no occupancy of activating marks. The H3K27me3 suppressive mark is consistently lower than the activation mark in the MUT.

for $\mathrm{H} 3 \mathrm{~K} 4 \mathrm{me} 3$ over the promoter from $-2,500 \mathrm{bp}$ to $+2,500 \mathrm{bp}$ relative to the transcription start and for $\mathrm{H} 3 \mathrm{~K} 27 \mathrm{me} 3$ over the gene body plus 2,500 bp upstream and $5,000 \mathrm{bp}$ downstream. The H3K4me3 activating marks are enriched on promoters of the upregulated genes, while there is little or no enrichment of the H3K27me3 suppressive marks. The genes downregulated in the mRNA array have diminished H3K4me3-activating marks and enrichment of H3K27me 3 suppressive marks. Figure 7 shows the pattern of modifications on the upregulated genes validated previously by qRT-PCR. The highly upregulated genes in the mutant cells display increased presence of the H3K4me3 activation mark on the promoter and, in the case of Vpreb1, Vpreb3 and Igll1, throughout the gene (Fig. 7). In wild-type cells, these genes have low or no occupancy of activating marks. Further, the H3K27me3 suppressive mark is consistently lower than the activation mark in the mutant. In summary, the mRNA array, qRT-PCR and ChIP-Seq results demonstrate that genes important for commitment to early B-cell development are markedly upregulated, whereas genes associated with other haematopoietic lineages are repressed when compared with control mice. Thus, deletion of RBP-J in renin-expressing haematopoietic precursors leads to enrichment of precursor B-lineage genes at the expense of alternative cell fates, a process facilitated by epigenetic changes.

Gene set enrichment analysis (GSEA) is a computational method that determines whether defined gene signatures are differentially expressed between two groups ${ }^{17}$. Using a canonical pathway knowledge database containing 880 known gene sets, we performed GSEA on our gene expression data comparing the expression pattern in spleens from mice with leukaemia versus control mice. Cells from mice with leukaemia were enriched in gene signatures associated with cell cycle progression (Supplementary Fig. 9a and Supplementary Table 2). Flow cytometry confirmed that mutant cells have an increased percentage of cells in the $\mathrm{S}$ and $\mathrm{G} 2 / \mathrm{M}$ phases compared with control cells, indicating enhanced cell division as a result of RBP-J deletion (Supplementary Fig. 9b,c). Further, phosphohistone H3 staining showed a higher number of cells undergoing proliferation in leukaemic versus control mice (Supplementary Fig. 9d,e). These results indicate that deletion of $R B P-J$ promotes cell cycle progression and cellular proliferation in $\mathrm{B}$ cells. Together, these results show that silencing of $R B P-J$ in reninexpressing cells restricts the lineage potential of these progenitors to a precursor B-cell fate and alters the regulation of cell cycle progression ultimately leading to leukaemic transformation.

Mutations of $R B P-J$ in patients with lymphoid malignancies. Given the striking findings encountered in our mice, we investigated whether mutations of $R B P-J$ are present in human haematological malignancies. We performed $R B P-J$ exon sequencing in 44 patients with confirmed haematopoietic malignancies (Supplementary Table 3). A total of 10 patients (23\%) had variants in the coding region of RBP-J (Supplementary Table 4). We identified nine different predicted missense mutations and two frameshift deletions (Supplementary Fig. 10a). One deletion recurred in five patients, causing a frameshift at position 188 of the coding region, which is predicted to result in a 104 aminoacid truncated protein. These variants occurred in highly conserved regions of $R B P-J$ and are novel as none of them were found in a large number of normal genomes including 1000 Genomes Project, NCBI Single-Nucleotide Polymorphism database (dbSNP) and NHLBI Exome Sequencing Project (ESP5400). Finally, many of the missense variants are predicted to be damaging to the protein product as determined by multiple prediction models including AVSIFT, SIFT, PolyPhen2, LRT and Mutation Taster (Supplementary Table 4). Of note, RBP-J variants occurred in both B-cell and myeloid malignancies (Supplementary Fig. 10b).

\section{Discussion}

Mice with deletion of $R B P-J$ in renin cells develop precursor $\mathrm{B}$-cell leukaemia. The cell of origin for this leukaemia is a novel renin-expressing haematopoietic progenitor with a B-lymphocyte pedigree, which we have termed the $\mathrm{B}^{\text {renin }}$-cell. Deletion of RBP-J in these precursors leads to enrichment of the genetic programme for B-cell commitment, enhanced cell cycle progression and proliferation, infiltration of multiple organs and early death. Leukaemic cells have clonal IgH rearrangements, can be cultured for multiple passages, are transplantable in irradiated animals and can be recovered from recipient mice and further grown in culture.

To our knowledge, this is the first report demonstrating RBP-J silencing as an initiating event in B-cell leukaemogenesis. Radke et al. ${ }^{18}$ showed that deletion of Notch 1 in adult bone marrow results in enhanced B-cell development, but not overt leukaemia. 
Han et al. ${ }^{11}$ used $M x$-Cre mice to delete RBP-J in adult bone marrow cells resulting in blockade of $\mathrm{T}$-cell development and increase in B-cell development within the thymus, but not leukaemia. Finally, Tanigaki et al. ${ }^{19}$ deleted RBP-J in B-cells by targeting the B-cell lineage marker CD19, leading to enhanced follicular B-cell populations with loss of marginal zone B-cells but no leukaemia phenotype. Remarkably, deletion of RBP-J in $\mathrm{B}^{\text {renin }}$ cells leads to overt leukaemia suggesting that these reninexpressing cells are particularly vulnerable to transformation. However, we have not excluded the possibility that the precursor B leukaemia observed in the current study reflects strain differences in our mice compared with other conditional models of RBP-J deletion that do not result in leukaemia.

The existence of a local bone marrow renin-angiotensin system (RAS) has previously been described ${ }^{20}$. Components of the RAS are present in bone marrow cells with putative roles in both normal and neoplastic haematopoiesis ${ }^{21-24}$. While the presence of renin in the bone marrow has been suggested, the identity and function of renin cells during haematopoiesis were unknown. In our study, we found that $\mathrm{B}^{\text {renin }}$-cells decrease from $\sim 20$ to $\sim 1 \%$ in the normal bone marrow and from $\sim 20$ to $\sim 5 \%$ in the spleen by 6 months of age. Further, a related member of the RAS, angiotensin-converting enzyme (ACE), has been well characterized as a marker of haematopoietic stem cells during both fetal and adult life ${ }^{25,26}$. It is therefore possible that $\mathrm{B}^{\text {renin }}$ cells may be remnants of embryonic haematopoiesis or that renin marks a specific stem cell population with differential transforming capacity, accounting for the difference between models ${ }^{27}$, and suggesting that the phenotype caused by loss of $R B P-J$ in haematopoietic cells depends on the cell of origin. Together with previous studies, our findings suggest that renin and the RAS may play critical roles in haematopoietic ontogeny and HSC plasticity.

We found remarkable developmental, biochemical/ transcriptional and functional similarities between the $\mathrm{B}^{\text {renin }}$-cell and its seemingly more distant kidney renin cell. Similar to their kidney cell counterpart, $\mathrm{B}^{\text {renin }}$-cells in the bone marrow and spleen also decrease in number as development proceeds and are responsive to physiological challenges: captopril treatment as well as life-time deletion of the Ren $1^{d}$ gene disturbs circulatory and fluidelectrolyte homeostasis and induce an increase in $\mathrm{GFP}^{+}$cells in the bone marrow and the circulation indicating that reninexpressing haematopoietic cells respond to systemic and/or local physiological cues, such as lack of angiotensin, in a manner not dissimilar to the JG cell ${ }^{6}$. $\mathrm{B}^{\text {renin }}$-cells and JG renin cells also share numerous transcriptional regulators, notably EBF1, a known regulator of lymphocyte development, members of the Notch pathway including ligands and receptors and the final transcriptional effector, $R B P-J^{14}$. These observations suggest conservation of the regulatory machinery and a possible lineage relationship between the two cell types. The functional relevance of these findings is underscored by the fact that both cell types need RBP-J to differentiate and function properly: lack of RBP-J in kidney renin cells results in a significant decrease in the number of renin cells and loss of the descendant's memory to regain the renin phenotype. Similarly, mutant $B^{\text {renin }}$-cells lose their differentiation potential, are retained in a precursor stage and lose control of their normal cell cycle leading to neoplastic transformation. In both cases, RBP-J regulates cell fate.

What is the local function of renin precursors in these two tissues? In the kidney, renin cells control vascular development ${ }^{28-31}$. Although components of the renin-angiotensin system have been described in peripheral leukocytes ${ }^{22}$ and bone marrow ${ }^{23}$, the function of renin cells in haematopoietic tissues remains to be determined. It would be interesting to determine whether $\mathrm{B}^{\text {renin }}$ cells also participate in the coordinated systemic response to control circulatory and fluid-electrolyte homeostasis, or whether renin expression in the bone marrow serves some other role during primitive, definitive and neoplastic haematopoiesis ${ }^{23}$.

In this study, we found cooperative mechanisms for leukaemic transformation: upregulation of genes involved in B-cell specification and of genes involved in cell cycle progression. During normal haematopoiesis, Notch/RBP-J signalling favours T-cell development by repressing a network of transcription factors important for early B-cell commitment including EBF1 and $E 2 A^{27,32-34}$. These transcription factors in turn are responsible for activating transcription of several genes critical for early B-cell development, including Igll1, Rag1 and Vpreb1 (ref. 35). Deletion

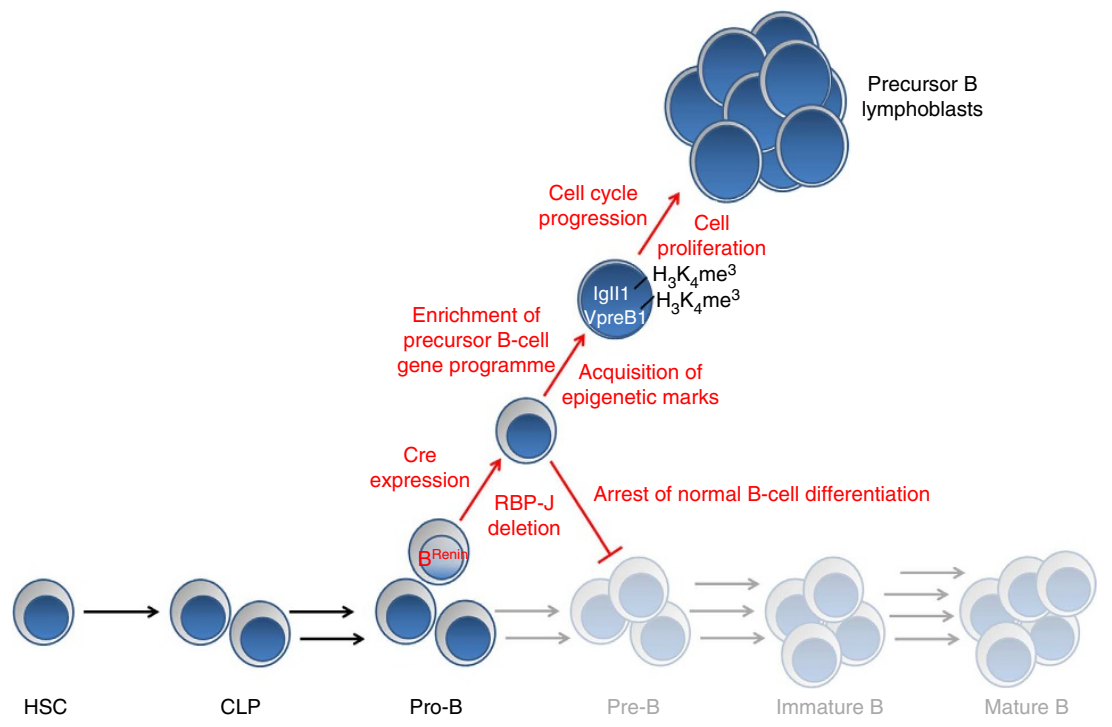

Figure 8 | Depiction of this model of lymphoblastic leukaemia. Normal B-cell development proceeds from haematopoietic stem cells (HSC) through multiple stages to ultimately become mature B cells. A small subset of pro-B cells express renin and are termed Benin -cells. In this model, activation of the renin promoter in $\mathrm{B}^{\text {Renin }}$-cells results in cre recombinase expression and subsequently RBP-J deletion. These cells fail to differentiate along the normal B-cell pathway, undergo epigenetic activation and enrichment of a precursor B-cell gene programme. Mutant cells additionally experience cell cycle progression and cell proliferation ultimately resulting in expansion of a lymphoblast population and the development of precursor B cell leukaemia. 
of $R B P-J$ in renin cells led to increased expression of those $\mathrm{B}$-lineage associated transcripts. These findings were correlated with ChIP-Seq data. H3K4me3 activating marks, which facilitate the opening of the chromatin structure to permit transcription, were present along those genes responsible for the pre B-cell genetic programme. Of note are the highly overexpressed genes Rag1, Vpreb1 and Vpreb3 that had H3K4 activation marks not only in the promoter but also along the entire body of gene reinforcing their open chromatin structure. In addition, the ChIPSeq data showed H3K27 repressive marks along genes from other lineages. Thus de-repression of the determinants of B-lineage commitment by deletion of $R B P-J$ appears to restrict progenitors to a precursor B-cell fate. Our array and GSEA analyses also demonstrated enrichment of genes involved in cell cycle progression. Genetic defects that cause a block in lymphocyte differentiation and progression of the G1/S cell cycle transition have been reported in lymphocytic leukaemia ${ }^{36,37}$. Similar to these findings, deletion of $R B P-J$ in $\mathrm{B}^{\text {renin }}$-cells leads to cell cycle progression and increased cellular proliferation, tissue infiltration and early death.

Mutations of RBP-J in humans have not been extensively studied: we could find only one report of an $R B P-J$ sequence mutation occurring in a haematologic malignancy ${ }^{38}$. Schuh et al. ${ }^{38}$ performed whole-genome sequencing to track the subclonal evolution of chronic lymphocytic leukaemia in three patients over different treatment time points. They identified a mutation occurring in RBP-J in a single patient, and, similar to our findings, this variant was present at a low frequency (1.16 to $6.69 \%$ over different time points). To further explore whether mutations in $R B P-J$ contribute to human disease, we sequenced the exome of $R B P-J$ in 44 bone marrow specimens from patients with haematopoietic malignancies. We found that a fraction of B-cell malignancies contained single-nucleotide variants in the coding regions of RBP-J. These variants occurred in conserved regions of the gene, have not previously been seen in a large number of healthy individuals and are predicted to have negative translational consequences. In addition, we detected RBP-J variants in myeloid leukaemia samples that support previous work demonstrating inactivating mutations of the Notch pathway in patients with chronic myelomonocytic leukaemia ${ }^{39}$. Several limitations of this study are worth noting. First, we did not have remission samples from these patients to confirm the somatic nature of these mutations. Second, the bone marrow samples likely included a mixed population of cells including normal haematopoietic cells and heterogeneous malignant subclones, which may have influenced the low variant allele frequency. However, the significant occurrence of these $R B P-J$ variants in a variety of haematologic malignancies in this and the aforementioned study ${ }^{38}$ and the fact that these variants have not been previously detected in healthy individuals suggest that mutations of $R B P-J$ should be further studied to define whether they indeed contribute to disease development, maintenance or progression in humans.

In summary, we identified novel bone marrow progenitors, which express renin and become the source of lymphoblastic leukaemia when RBP-J is missing (Fig. 8). The possibility that within the B-cell population there are subsets of progenitors with differential transformative capacity has significant implications for understanding the origin of leukaemia. The discovery of these progenitors, the reproducibility of this highly penetrant mouse model of leukaemia, and the generation of a new GFP labelled leukaemia cell line offer an invaluable opportunity to explore the mechanisms responsible for normal and neoplastic haematopoiesis.

\section{Methods}

Generation of study mice. To inactivate RBP-J in renin-lineage cells, we crossed Ren $1^{\text {dcre/ }}+$ mice $^{1}$, which express Cre recombinase in renin cells, to RBP-J floxed
$\left(R B P-f^{f l / f l}\right)$ mice (a kind gift from T Honjo) ${ }^{11}$. Mice carrying both $R B P-f^{f l / f l}$ and Ren $1^{\text {dcre/ }+}$ undergo Cre-mediated recombination specifically in cells that express renin leading to deletion of $R B P-J^{11,19} . R B P-f^{f l+} ; R e n 1^{d c r e /+}$ mice were mated to generate $R B P-f^{f l f l} ; \operatorname{Ren} 1^{d+/+}$ (control) and $R B P-f^{f l / f l} ; \operatorname{Ren} 1^{d c r e /+}$ (mutant) mice. For genotyping, genomic DNA was extracted and purified from tail biopsies using Quiagen DNeasy Blood and Tissue kit (Valencia, CA) according to the manufacturer's instructions, and standard PCR was performed in an Eppendorf thermocycler using Taq polymerase (Promega, Madison, WI). The primers used for genotyping were: wild-type renin forward $5^{\prime}$-GAAGGAGAG CAAAAGGTA AGAG-3', wild-type renin reverse $5^{\prime}$-GTAGTAGAAGGGGGAGTTGTG-3', Ren $1^{\text {dcre }}$ forward 5'-GAAGGAGAGCAAAAGGTAAGAG-3', Ren $1^{\text {dcre }}$ reverse $5^{\prime}$ TTGGTGTACGGTCAGTAAATTGGAC-3' $3^{\prime}$, wild-type $R B P$ - $J$ forward $5^{\prime}$-GTTCT TAACCTGTTGGTCGGAACC-3' ${ }^{\prime}$, wild-type $R B P-J$ reverse $5^{\prime}$-GCTTGAGGCTT GATGTTCTGTAATGC-3', floxed RBP-J forward $5^{\prime}$-GTTCTTAACCTGTTGGTC GGAACC- $3^{\prime}$, and floxed $R B P-J$ reverse $5^{\prime}$-GCAATCCATCTTGTTCAATGGCC- $3^{\prime}$ (ref. 10). Lineage tracing was performed to determine the pattern of renin expression in the bone marrow and spleen. Ren $1^{d c r e /+}$ mice were bred to the lineage reporter line $m T / m G^{12}$. In this reporter, non-recombined cells express RFP, and following Cre-mediated recombination GFP is expressed in renin-lineage cells and their descendants. This line was used to isolate renin-lineage cells in normal mice and in mice with $R B P-J$ deletion within renin cells. Ren $1^{c}-Y F P$ transgenic mice were used to isolate cells that actively express renin ${ }^{40}$. Finally, reninexpressing cells in the bone marrow were isolated for gene array studies from transgenic Bac-Ren1 $1^{c}$-GFP mice ${ }^{16}$. Flow cytometry and immunofluorescence experiments involving renin-expressing and renin-lineage reporters were performed on both male and female mice between the age of 2 weeks and 3 months. To determine the relative fraction of renin cells within the bone marrow and spleen at different developmental stages, renin-expressing and renin-lineage mice were evaluated at different ages between 2 weeks and 200 days of life.

Mutant mice were monitored until they developed signs and symptoms of disease. When they became moribund, they were anaesthetized with tribromoethanol $\left(300 \mathrm{mg} \mathrm{kg}^{-1}\right)^{41}$, and organs were removed, preserved for RNA extraction, fixed for immunohistochemistry or immunofluorescence, or processed for flow cytometry. Twenty-four mutant mice are included in this study with equal numbers of age-matched control animals. Study animals included both males and females. All procedures were performed in accordance with the National Institutes of Health guidelines for the care and use of laboratory animals and were approved by The Animal Care and Use Committee of the University of Virginia.

Identification of cell phenotypes by flow cytometry. To determine the subtype of leukaemia and characterize its cell of origin, flow cytometry analysis was performed. Single-cell suspensions were obtained from the bone marrow, spleen and tumours found in the abdomen and axillary regions. To obtain bone marrow cells, the long bones of mice were dissected, flushed with cell suspension media (Biolegends, San Diego, CA), and the cells were passed through a $70 \mu \mathrm{m}$ strainer. Spleens or tumours were dissected cleanly, placed on a $70 \mu \mathrm{m}$ strainer and, using the plunger end of a syringe, gently passed through the strainer. The tissue was rinsed with cell staining buffer (CSB) (Biolegends) and the process repeated until the spleen capsule turned clear. All cells were treated with RBC lysis buffer (Sigma, St Louis, MO), resuspended in CSB, counted using a haemocytometer and distributed into microcentrifuge tubes for antibody labelling against the surface markers in Supplementary Table 5 (all antibodies were purchased from Biolegends except CD43, which was purchased from Becton Dickinson, Franklin Lakes, NJ). Antibodies were added at predetermined optimum concentrations (Supplementary Table 5) and incubated at room temperature for $20 \mathrm{~min}$. Immunophenotyping was performed in the UVA Flow Cytometry core lab using a Fortessa cytometer and data analysed with FlowJo program.

Identification of RBP-J deletion in peripheral blood. To mark with GFP and indirectly evaluate the deletion of $R B P-J$ in circulating leukocytes, $0.5 \mu \mathrm{l}$ of blood from $R B P-f^{f l / f l} ;$ Ren $1^{d c r e /+} ; m T / m G$ and $R B P-J^{+/+} ;$Ren $1^{d c r e /+} ; m T / m G$ mice was obtained by a small cut of the tip of the tail, collected using heparinized pipette tips and diluted in $100 \mu \mathrm{l}$ of cold PBS in a 96-well plate. Using an inverted microscope (Leica DMIRE2) recombined $\left(\mathrm{GFP}^{+}\right)$and not recombined $\left(\mathrm{RFP}^{+}\right)$cells were counted in three fields using a $\times 20$ objective and pictures were taken using a Retiga EXi camera (Q-Imaging, Surry, BC).

RNA extraction and PCR analysis. Total RNA was isolated from the whole bone marrow, spleen and tumour samples using Trizol extraction (Life Technologies, Grand Island, NY) according to the manufacturer's instructions. cDNA was prepared from $2 \mu \mathrm{g}$ of RNA using Moloney murine leukaemia virus reverse transcriptase (Life Technologies, Grand Island, NY) and an oligo(dT) primer according to the manufacturer's instructions. PCR was performed on $2 \mu \mathrm{l}$ of cDNA using Taq DNA polymerase (Promega, Madison, WI) ${ }^{40}$.

For validation of microarray data, $\mathrm{qPCR}$ was performed using SYBR Green 1 (Invitrogen Molecular Probes, Eugene, OR) in a CFXConnect system (Biorad, Hercules, CA $)^{42}$. Primers are listed in Supplementary Table 6. 
Histologic analysis. Immunohistochemistry was performed on Bouin's and formalin-fixed tissue. In brief, 5- $\mu \mathrm{m}$ tissue sections were deparaffinized in xylenes and graded alcohols. Sections were incubated overnight with primary antibodies against PAX5 (BD Clone 24/Pax5, dilution 1:40), CD79a (Dako Clone JCB117, dilution 1:400), TdT (Cell Marque polyclonal, ready to use), CD34 (Dako Clone QBEnd10, dilution 1:100) and Phosphohistone H3 (Cell Signaling Technologies, dilution 1:200), and antibody binding was visualized using the Vectastain ABC kit (Vector Laboratories, Burlingame, CA). Sections were counter-stained with haematoxylin, dehydrated through graded alcohols to xylenes and mounted with Permount.

Immunofluorescence was performed on frozen sections using a primary antibody against IgM (Biolegends, dilution 1:10). Sections were washed with PBS then blocked for $1 \mathrm{~h}$ using $10 \%$ BSA in PBS with $1 \%$ normal donkey serum. The primary antibody was incubated overnight at $4{ }^{\circ} \mathrm{C}$ then incubated with a fluorescently conjugated secondary antibody (AlexaFluor 350, Invitrogen, 1:500).

Immunoglobulin gene rearrangement analysis. Genomic DNA from the bone marrow, spleen and tumour samples was used as templates for PCR amplification. Primer pairs used were DQ52 for $5^{\prime}$-CCACAGGCTCGAGAACTTTAGCG- $3^{\prime}$; $\mathrm{J}_{\mathrm{H}} 4$ Rev $5^{\prime}$-AGGCTCTGAGATCCCTAGACAG-3' to detect D-J recombination products; $\mathrm{V}_{\mathrm{H}} 7183$ for $5^{\prime}$-GTGGAGTCTGGGGGAGGCTTA-3'; $\mathrm{J}_{\mathrm{H}} 4$ Rev $5^{\prime}$-AGGCTCTGAGATCCCTAGACAG- $3^{\prime}$ to detect V-DJ products; DLG5 for 5'-AAGTCTCAGGCTGGCCATTA-3'; DLG5 Rev 5' -TTTACCACCCCTGAC ACACA- $3^{\prime}$ to amplify a single-copy gene used for normalization of DNA amount ${ }^{43}$. The PCR reaction was performed in a $50 \mu \mathrm{l}$ volume containing $100 \mathrm{ng}$, $33 \mathrm{ng}$ or $11 \mathrm{ng}$ of template DNA, $1 \times$ PCR buffer, $1.5 \mathrm{mM} \mathrm{MgCl}_{2}, 0.2 \mathrm{mM}$ dNTPs, $0.4 \mu \mathrm{mM}$ each primer and $0.75 \mathrm{U}$ Taq polymerase (Promega Corporation, Madison, WI). Thermocycling conditions were as follows: $4 \mathrm{~min}$ at $95^{\circ} \mathrm{C}$ followed by $31 \mathrm{cycles}$ of $30 \mathrm{~s}$ at $95^{\circ} \mathrm{C}, 90 \mathrm{~s}$ at $60^{\circ} \mathrm{C}, 2 \mathrm{~min}$ at $72^{\circ} \mathrm{C}$ and a final extension step of $5 \mathrm{~min}$ at $72^{\circ} \mathrm{C}$. Products ( 15 or $20 \mu \mathrm{l}$ of the PCR reaction) were separated on $1 \%$ agarose gels, transferred to GeneScreen Plus Hybridization Transfer Membrane (Perkin Elmer, Waltham, MA) and hybridized at $42^{\circ} \mathrm{C}$ to $\mathrm{J}_{\mathrm{H}}$ probe $5^{\prime}$-TATG GACTACTGGGGTCAAGGAA- $3^{\prime}$ end labelled with ${ }^{32} \mathrm{P}$-ATP using $20 \mathrm{U}$ of T4 polynucleotide kinase (New England Biolabs, Ipswich, MA). Membranes were washed with $2 \times$ SSC, $0.1 \%$ SDS and exposed to Kodak Biomax MS film.

Cell cycle analysis. The DNA content of fixed cells from the bone marrow and spleen was determined using propidium iodide (PI) staining ${ }^{44}$. Single-cell suspensions from the spleen and bone marrow were obtained as described above. The cells were counted using a haemocytometer, and $1 \times 10^{6}$ cells were fixed and stored in $70 \%$ ethanol at $4{ }^{\circ} \mathrm{C}$. On the day of cell cycle analysis, the fixed cells were resuspended in $5 \mathrm{ml}$ PBS, centrifuged $5 \mathrm{~min}$ at $200 \times \mathrm{g}$ and resuspended in $1 \mathrm{ml}$ of PI staining solution (10 ml of TritonX-100 PBS, $2 \mathrm{mg}$ DNase-free RNase A and $200 \mu \mathrm{l}$ of $1 \mathrm{mg} \mathrm{ml}^{-1} \mathrm{PI}$ ). Cells were incubated in PI solution for $30 \mathrm{~min}$ at room temperature, and DNA content was determined using flow cytometry.

In vitro colony-forming assay. To determine the growth characteristics of reninlineage cells, bone marrow cells from Ren $1^{\text {dcre/ }+} ; m T / m G$ reporter mice were grown in methylcellulose with medium permissive for either B-lymphocyte or myeloid-erythroid colony growth (Methocult GF medium for mouse Pre-B cells M3630, and Methocult GF for mouse haematopoietic progenitors, M3434, Stem Cell Technologies Vancouver, BC, Canada). Cells were diluted in Iscove's MDM with $5 \% \mathrm{FBS}$, and plated in duplicate samples at $1 \times 10^{5}$ cells per $30 \mathrm{~mm}$ plate. After incubation for 14 days at $37^{\circ} \mathrm{C}$ in $5 \%$ humidified $\mathrm{CO}_{2}$, plates were visualized using inverted microscopy (Leica DMIRE2) and colony-forming units (CFUs) were scored according to standard criteria ${ }^{45}$. The percent of $\mathrm{GFP}^{+}$(renin-lineage) colonies was quantitated in both B-cell and myeloid/erythroid permissive culture conditions.

Transplantation studies. Leukaemic B cells that express GFP were purified from methylcellulose cultures and injected intravenously at a dose of $2-6 \times 10^{6}$ cells into irradiated mice (13 Gy) $(n=3)$. Recipients were monitored closely and killed at 1 week post injection. Control animals included non-irradiated mice that received leukaemic cell injections, and irradiated mice that received vehicle only (media)

Gene expression analysis. RNA was isolated from spleens from mutant and control mice. Hybridization to the Affymetrix mouse gene array ST1.0 was performed by the UVA Core Lab Microarray Facility. All preprocessing and analysis were done using $\mathrm{R}$ version 2.15.0. CEL files were imported using the Affymetrix package, version 1.34.0. Expression intensities were summarized, normalized and transformed using Robust Multiarray Average algorithm ${ }^{46}$. Probesets were annotated using the BioConductor annotation package mogene10sttranscriptcluster.db version 8.0.1, annotate package, version 1.34.0. Linear models with empirical Bayes moderated standard errors were fit using the BioConductor limma package version 3.12.1. False discovery rate was used to correct for multiple testing. Gene set enrichment analysis was used to examine coordinated gene expression changes in canonical pathways using the Molecular Signatures Database curated canonical pathway gene set ${ }^{17,47}$. GEO accession: GSE46229.
RNA was extracted from renin-expressing bone marrow cells isolated from Bac-Ren $1^{c}$-GFP mice using a Becton-Dickinson Aria 2 cell sorter in the RPCI Flow Cytometry Core Facility. RNA from unsorted bone marrow and $\mathrm{GFP}^{+}$cells was hybridized to MOE430 V2.0 oligonucleotide microarray GeneChip Arrays (Affymetrix) in the RPCI Gene Expression Facility. The results from the three replicates were normalized using RMA and quantile. GEO accession: GSE53916.

Chromatin immunoprecipitation and next generation sequencing. Chromatin immunoprecipitation (ChIP-Seq) was performed by Active Motif (Carlsbad, CA) Chromatin $(30 \mu \mathrm{g})$ from control and mutant spleens was precipitated with antibodies against $\mathrm{H} 3 \mathrm{~K} 4 \mathrm{me} 3$, a marker of active genes ( $2 \mu \mathrm{l}$, AM 39159) and H3K27me3, a marker of inactive genes ( $4 \mu \mathrm{l}$, Millipore 17-449). ChIP DNA was processed into Illumina libraries using standard procedures, and libraries were sequenced on HiSeq 2000. The 50-nt sequence reads were mapped to the mouse $\mathrm{mm} 9$ genome using the BWA algorithm with default settings. For the analysis, all data files were normalized to the same number of unique alignments without duplicate reads (17.5 million). Sequence tags were extended in silico (using Active Motif software) at their $3^{\prime}$-ends to a length of $200 \mathrm{bp}$. To identify the density of fragments (extended tags) along the genome, the genome was divided into 32-nt bins and the number of fragments in each bin was determined. The resulting histogram files were used to extract average fragment density values for predefined promoter and gene regions. For $\mathrm{H} 3 \mathrm{~K} 4 \mathrm{me} 3$, promoter regions from $-2,500 \mathrm{bp}$ to $+2,500$ bp relative to the transcription start sites were used. However, for Vpreb1, the promoter regions were restricted to $-500 \mathrm{bp}$ to $+500 \mathrm{bp}$ relative to the transcription start site to discriminate Vprebl from the nearby gene, Top $3 b$. For $\mathrm{H} 3 \mathrm{~K} 27 \mathrm{me} 3$, gene regions plus 2,500 bp upstream and 5,000 bp downstream flanking regions were used. In this approach, the same genomic segments are compared between the Mutant and Control data sets, and the ratio of average fragment densities is a valid metric for comparison. In parallel, genomic regions with significant enrichments in tag numbers were identified using the SICER peak finding algorithm49 (cutoff FDR, 1E-10). Only genes with SICER peaks were included in the ratio calculation described above and shown in the Table 2. GEO accession: GSE46566.

RBP-J Sequencing in Human Bone Marrow Specimens. To identify mutations in $R B P-J$ that may be causing loss of function in human disease, we performed $R B P-J$ exon sequencing in the bone marrow from patients with haematopoietic malignancies. Genomic DNA was isolated from 140 bone marrow samples using the Qiagen DNAeasy kit, and 84 samples were suitable for sequencing. Amplicons were designed Using TruSeq Custom Amplicon design studio to cover the coding regions of $R B P-J$ and exome enrichment was performed. After PCR amplification, each exon was sequenced using an Illumina MiSeq instrument with paired-end 151 base pair reads. Data were aligned using MiSeq Reporter version E. All variants that were non-synonymous were evaluated for significance. Of these 84 samples, 44 patients had a definitive diagnosis of haematopoietic malignancy available in their medical record and were included in our analysis. These studies were approved by the University of Virginia Institutional Review Board for Health Science Research. The project met criteria of research involving coded biological specimens, and informed consent was not required.

Statistical analysis. Data are presented as means \pm s.e.m. Significance between groups was determined using the Mann-Whitney $U$-test and two-tailed Student's $t$-test using GraphPad Prism 5.0. Differences were considered statistically significant at the ${ }^{\star} P<0.05 ;{ }^{*} P<0.01$ and ${ }^{* * *} P<0.001$ levels.

\section{References}

1. Sequeira Lopez, M. L., Pentz, E. S., Nomasa, T., Smithies, O. \& Gomez, R. A. Renin cells are precursors for multiple cell types that switch to the renin phenotype when homeostasis is threatened. Dev. Cell 6, 719-728 (2004).

2. Gomez, R. A. et al. Renin and angiotensinogen gene expression in maturing rat kidney. Am. J. Physiol. 254, F582-F587 (1988).

3. Gomez, R. A. et al. Distribution of renin mRNA and its protein in the developing kidney. Am. J. Physiol. 257, F850-F858 (1989).

4. Jones, C. A., Sigmund, C. D., McGowan, R. A., Kane-Haas, C. M. \& Gross, K W. Expression of murine renin genes during fetal development. Mol. Endocrinol. 4, 375-383 (1990).

5. Mullins, J. J., Sigmund, C. D., Kane-Haas, C., Gross, K. W. \& McGowan, R. A. Expression of the DBA/2J Ren-2 gene in the adrenal gland of transgenic mice. EMBO J. 8, 4065-4072 (1989).

6. Gomez, R. A. et al. Recruitment of renin gene-expressing cells in adult rat kidneys. Am. J. Physiol. 259, F660-F665 (1990).

7. Jones, C. A. et al. Expression of a renin/GFP transgene in mouse embryonic, extra-embryonic, and adult tissues. Physiol. Genomics 4, 75-81 (2000).

8. Berg, A. C., Chernavvsky-Sequeira, C., Lindsey, J., Gomez, R. A. \& SequeiraLopez, M. L. Pericytes synthesize renin. World J. Nephrol. 2, 11-16 (2013).

9. Tanigaki, K., Kuroda, K., Han, H. \& Honjo, T. Regulation of B cell development by Notch/RBP-J signaling. Semin. Immunol. 15, 113-119 (2003). 
10. Castellanos Rivera, R. M. et al. Transcriptional regulator RBP-J regulates the number and plasticity of renin cells. Physiol. Genomics 43, 1021-1028 (2011).

11. Han, H. et al. Inducible gene knockout of transcription factor recombination signal binding protein-J reveals its essential role in T versus B lineage decision. Int. Immunol. 14, 637-645 (2002).

12. Muzumdar, M. D., Tasic, B., Miyamichi, K., Li, L. \& Luo, L. A global doublefluorescent Cre reporter mouse. Genesis 45, 593-605 (2007).

13. Morse, III H. C. et al. Bethesda proposals for classification of lymphoid neoplasms in mice. Blood 100, 246-258 (2002).

14. Brunskill, E. W. et al. Genes that confer the identity of the renin cell. J. Am. Soc. Nephrol. 22, 2213-2225 (2011).

15. Hardy, R. R., Carmack, C. E., Shinton, S. A., Kemp, J. D. \& Hayakawa, K. Resolution and characterization of pro-B and pre-pro-B cell stages in normal mouse bone marrow. 1991. J. Immunol. 189, 3271-3283 (2012).

16. Glenn, S. T., Jones, C. A., Pan, L. \& Gross, K. W. In vivo analysis of key elements within the renin regulatory region. Physiol. Genomics 35, 243-253 (2008).

17. Subramanian, A. et al. Gene set enrichment analysis: a knowledge-based approach for interpreting genome-wide expression profiles. Proc. Natl Acad. Sci. USA 102, 15545-15550 (2005).

18. Radtke, F. et al. Deficient T cell fate specification in mice with an induced inactivation of Notch1. Immunity 10, 547-558 (1999).

19. Tanigaki, K. et al. Notch-RBP-J signaling is involved in cell fate determination of marginal zone B cells. Nat. Immunol. 3, 443-450 (2002).

20. Haznedaroglu, I. C. \& Beyazit, Y. Pathobiological aspects of the local bone marrow renin-angiotensin system: a review. J. Renin Angiotensin Aldosterone Syst. 11, 205-213 (2010)

21. Beyazit, Y. et al. Overexpression of the local bone marrow renin-angiotensin system in acute myeloid leukemia. J. Natl Med. Assoc. 99, 57-63 (2007).

22. Gomez, R. A. et al. Leukocytes synthesize angiotensinogen. Hypertension 21, 470-475 (1993)

23. Haznedaroglu, I. C. \& Beyazit, Y. Local bone marrow renin-angiotensin system in primitive, definitive and neoplastic haematopoiesis. Clin. Sci. (Lond) 124, 307-323 (2013)

24. Strawn, W. B., Richmond, R. S., Ann, T. E., Gallagher, P. E. \& Ferrario, C. M. Renin-angiotensin system expression in rat bone marrow haematopoietic and stromal cells. Br. J. Haematol. 126, 120-126 (2004).

25. Jokubaitis, V. J. et al. Angiotensin-converting enzyme (CD143) marks hematopoietic stem cells in human embryonic, fetal, and adult hematopoietic tissues. Blood 111, 4055-4063 (2008).

26. Sinka, L., Biasch, K., Khazaal, I., Peault, B. \& Tavian, M. Angiotensinconverting enzyme (CD143) specifies emerging lympho-hematopoietic progenitors in the human embryo. Blood 119, 3712-3723 (2012).

27. Ohishi, K., Katayama, N., Shiku, H., Varnum-Finney, B. \& Bernstein, I. D. Notch signalling in hematopoiesis. Semin. Cell Dev. Biol. 14, 143-150 (2003)

28. Reddi, V., Zaglul, A., Pentz, E. S. \& Gomez, R. A. Renin-expressing cells are associated with branching of the developing kidney vasculature. J. Am. Soc Nephrol. 9, 63-71 (1998).

29. Takahashi, N. et al. Ren1c homozygous null mice are hypotensive and polyuric, but heterozygotes are indistinguishable from wild-type. J. Am. Soc. Nephrol. 16, 125-132 (2005)

30. Tufro-McReddie, A. et al. Angiotensin II type 1 receptor: role in renal growth and gene expression during normal development. Am. J. Physiol. 266, F911-F918 (1994).

31. Tufro-McReddie, A., Romano, L. M., Harris, J. M., Ferder, L. \& Gomez, R. A. Angiotensin II regulates nephrogenesis and renal vascular development. Am. J. Physiol. 269, F110-F115 (1995).

32. Pajcini, K. V., Speck, N. A. \& Pear, W. S. Notch signaling in mammalian hematopoietic stem cells. Leukemia 25, 1525-1532 (2011).

33. Tanigaki, K. \& Honjo, T. Regulation of lymphocyte development by Notch signaling. Nat. Immunol. 8, 451-456 (2007).

34. Zandi, S. et al. EBF1 is essential for B-lineage priming and establishment of a transcription factor network in common lymphoid progenitors. J. Immunol. 181, 3364-3372 (2008).

35. Smith, E. M., Akerblad, P., Kadesch, T., Axelson, H. \& Sigvardsson, M. Inhibition of EBF function by active Notch signaling reveals a novel regulatory pathway in early B-cell development. Blood 106, 1995-2001 (2005).

36. Bungaro, S. et al. Integration of genomic and gene expression data of childhood ALL without known aberrations identifies subgroups with specific genetic hallmarks.. Genes Chromosomes Cancer 48, 22-38 (2009).

37. Kuiper, R. P. et al. High-resolution genomic profiling of childhood ALL reveals novel recurrent genetic lesions affecting pathways involved in lymphocyte differentiation and cell cycle progression. Leukemia 21, 1258-1266 (2007).
38. Schuh, A. et al. Monitoring chronic lymphocytic leukemia progression by whole genome sequencing reveals heterogeneous clonal evolution patterns. Blood 120, 4191-4196 (2012).

39. Klinakis, A. et al. A novel tumour-suppressor function for the Notch pathway in myeloid leukaemia. Nature 473, 230-233 (2011).

40. Pentz, E. S., Sequeira Lopez, M. L., Cordaillat, M. \& Gomez, R. A. Identity of the renin cell is mediated by cAMP and chromatin remodeling: an in vitro model for studying cell recruitment and plasticity.. Am. J. Physiol. Heart Circ Physiol. 294, H699-H707 (2008).

41. Sequeira Lopez, M. L., Pentz, E. S., Robert, B., Abrahamson, D. R. \& Gomez, R A. Embryonic origin and lineage of juxtaglomerular cells. Am. J. Physiol. Renal Physiol. 281, F345-F356 (2001).

42. Gomez, R. A., Pentz, E. S., Jin, X., Cordaillat, M. \& Sequeira Lopez, M. L. CBP and p300 are essential for renin cell identity and morphological integrity of the kidney. Am. J. Physiol. Heart Circ. Physiol. 296, H1255-H1262 (2009).

43. Perlot, T. et al. Analysis of mice lacking DNaseI hypersensitive sites at the $5^{\prime}$ end of the IgH locus. PLoS One 5, e13992 (2010).

44. Darzynkiewicz, Z. \& Juan, G. DNA content measurement for DNA ploidy and cell cycle analysis. Curr. Protoc. Cytom. Chapter 7 Unit (2001).

45. Miller, C. L. \& Lai, B. Human and mouse hematopoietic colony-forming cell assays. Methods Mol. Biol. 290, 71-89 (2005).

46. Irizarry, R. A. et al. Summaries of Affymetrix GeneChip probe level data. Nucleic Acids Res. 31, e15 (2003)

47. Liberzon, A. et al. Molecular signatures database (MSigDB) 3.0. Bioinformatics 27, 1739-1740 (2011).

\section{Acknowledgements}

We thank Takele Yazew, Danielle Stumbo, Theodore Mehalic and Rajwinderjit Kaur for technical assistance and Cristina Monteagudo for genotyping. We are grateful to the Flow Cytometry Core Facility at the University of Virginia (Sebastian Coquery, Mike Solga, Joanne Lannigan and Lesa Campbell) for technical assistance and expert advice. We thank Yongde Bao of the DNA Science Core Facility and Patcharin Pramoonjago of the Biorepository and tissue research Core Facility at UVA for their expertise with gene array studies. We are very grateful to Wendy Golden and Kathy Burns from the department of Pathology for assisting with collection of human bone marrow specimens. We thank Tim Bender for reading the manuscript and providing insightful suggestions and to Professor T. Honjo for the gift of the RBP-J floxed mice. This research was supported by the University of Virginia Children's Medical Center internal grant support (BCB and RAG), the Karen Jargowsky Research Fund (BCB), and the National Institutes of Health (grants RO1 DK 091330 to MLSSL and Merit Award R37 HL 066242 to RAG).

\section{Author contributions}

B.C.B. designed and performed experiments, analysed data and wrote the manuscript; F.X., M.L. and Y.H. performed experiments; P.L. and S.T. performed bioinformatics analysis; R.L. provided expert pathological assessment; S.M. performed validation studies and conceptualized diagrams; E.S.P. analysed epigenetic data; C.J. and J.D.T. performed experiments on Bac-ren-GFP mice and analysed data; K.W.G. designed experiments, supervised experiments at Roswell Park and suggested strategies; M.L.S.S.L. and R.A.G. jointly and equally conceived and supervised experiments, analysed data and wrote the manuscript.

\section{Additional information}

Accession codes: Microarray expression data have been deposited in the Gene Expression Omnibus database under accession: codes GSE46229 and GSE53916. The CHiP-sec data have been deposited in the Gene Expression Omnibus database under accession: code GSE46566.

Supplementary Information accompanies this paper at http://www.nature.com/nature communications.

Competing financial interests: The authors declare no competing financial interests.

Reprints and permission information is available online at http://npg.nature.com/ reprintsandpermissions.

How to cite this article: Belyea, B. C. et al. Identification of renin progenitors in the mouse bone marrow that give rise to B-cell leukaemia. Nat. Commun. 5:3273 doi: $10.1038 /$ ncomms4273 (2014).

This work is licensed under a Creative Commons AttributionNonCommercial-NoDerivs 3.0 Unported License. To view a copy of it http://creativecommons.org/licenses/by-nc-nd/3.0/ 